Published in final edited form as:

Biochemistry. 2016 June 07; 55(22): 3136-3149. doi:10.1021/acs.biochem.6b00359.

\title{
Nuclear Magnetic Resonance Structure of a Major Lens Protein, Human $\gamma$ C-Crystallin: Role of the Dipole Moment in Protein Solubility
}

\author{
Karuna Dixit ${ }^{\dagger}$, Ajay Pande ${ }^{\ddagger}$, Jayanti Pande ${ }^{\star}, \neq, \S$, and Siddhartha P. Sarma ${ }^{\star}, \dagger$ \\ †Molecular Biophysics Unit, Indian Institute of Science, Bangalore, Karnataka 560012, India \\ ‡Department of Chemistry, University at Albany, State University of New York, Albany, New York \\ 12222, United States
}

\begin{abstract}
A hallmark of the crystallin proteins is their exceptionally high solubility, which is vital for maintaining the high refractive index of the eye lens. Human $\gamma \mathrm{C}$-crystallin is a major $\gamma$-crystallin whose mutant forms are associated with congenital cataracts but whose three-dimensional structure is not known. An earlier study of a homology model concluded that human $\gamma \mathrm{C}$-crystallin has low intrinsic solubility, mainly because of the atypical magnitude and fluctuations of its dipole moment. On the contrary, the high-resolution tertiary structure of human $\gamma \mathrm{C}$-crystallin determined here shows unequivocally that it is a highly soluble, monomeric molecule in solution. Notable differences between the orientations and interactions of several side chains are observed upon comparison to those in the model. No evidence of the pivotal role ascribed to the effect of dipole moment on protein solubility was found. The nuclear magnetic resonance structure should facilitate a comprehensive understanding of the deleterious effects of cataract-associated mutations in human $\chi$ C-crystallin.
\end{abstract}

\section{Graphical abstract}

${ }^{*}$ Corresponding Authors jpande@albany.edu. sidd@mbu.iisc.ernet.in.

$\S$ This work was begun when J.P. was on sabbatical at the Indian Institute of Science, during the 2014-2015 academic year.

Supporting Information

The Supporting Information is available free of charge on the ACS Publications website at DOI: 10.1021/acs.biochem.6b00359.

Figures providing corroborative evidence for the data shown in the manuscript (PDF)

Accession Codes

The structural coordinates for the 20 low-energy structures of HGC have been deposited in the Protein Data Bank as entry 2NBR. The chemical shift assignments for HGC have been deposited in the Biological Magnetic Resonance Bank as entry 25993.

The authors declare no competing financial interest. 


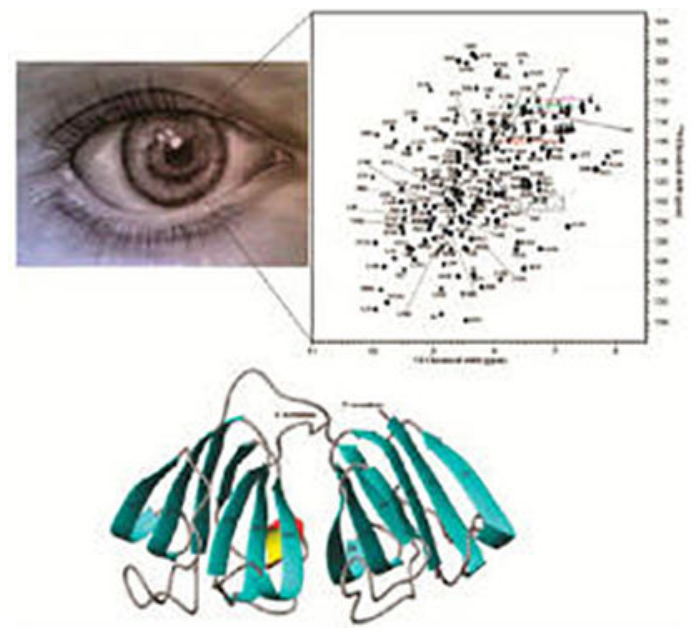

The $\gamma$-crystallin proteins in the ocular lens are characterized by very high solubility ${ }^{1-3}$ and a high refractive index. ${ }^{4}$ Among the $\gamma$-crystallins in the human lens, $\gamma \mathrm{S}$-crystallin (HGS), $\gamma \mathrm{C}$ crystallin (HGC), and $\gamma \mathrm{D}$-crystallin (HGD) are predominantly expressed. ${ }^{5-7}$ Of these, HGS is expressed postnatally and is present mainly in the cortical or outer region of the lens, while HGC and HGD are the major $\gamma$-crystallins in the nucleus or inner region. It is wellknown that mutant $\gamma$-crystallins associated with cataract ${ }^{8}$ often show a dramatically lowered protein solubility, even though their structures are minimally perturbed. ${ }^{9-12}$ In fact, lowered solubility and lowered stability are two important parameters generally used to explain the molecular basis of crystallin-associated cataracts. ${ }^{13,14}$ Because nuclear cataract is the most common form of human cataract, ${ }^{15}$ it is imperative that the structures, stabilities, and solubility properties of the $\gamma$-crystallins located in the lens nucleus be examined. Unlike the case for HGD and HGS,,${ }^{9,16-19}$ very little is known about HGC. In an earlier study, ${ }^{20}$ a homology model of HGC based on the X-ray crystal structure of the orthologous mouse protein was used to provide a comprehensive comparison of the physicochemical properties of the mouse and human $\mathcal{C}$-crystallins. Surprisingly, in contrast to other lens crystallins, Purkiss et al. found that the solubility of native HGC relative to that of the orthologous MGC is drastically lowered. Furthermore, from the modeled structure of the human protein and molecular dynamics simulations, the authors concluded that the small magnitude of the dipole moment of the $\mathrm{N}$-terminal domain, and its highly variable orientation in solution, may be responsible for the lowered solubility of HGC, and the observed propensity for aggregation in solution. The authors also attribute the inability to obtain suitable single crystals of HGC for X-ray diffraction studies to its putative lowered solubility.

These observations on the native form of HGC are inconsistent with earlier reports on a cataract-associated mutant, T4P, of HGC that has clearly been shown to have a severely compromised solubility ${ }^{21}$ compared to that of the native protein, although in that work, the authors dealt with only relatively low concentrations $(1-2 \mathrm{mg} / \mathrm{mL})$ of the native protein.

Thus, while many cataract-associated mutations in HGD and HGC lead to lowered solubility, ${ }^{14,21} \mathrm{HGC}$ is the only example of a native crystallin that apparently exhibits such a compromised solubility. ${ }^{20}$ The absence of any teleological explanation for the lowered 
solubility of a native crystallin protein motivated us to reexamine the solubility and to determine the three-dimensional (3D) NMR structure and dynamics of this protein.

In this report, we show that HGC can be expressed, isolated, and purified in a form that appears to be as soluble as other native crystallins. The tertiary structure in solution has been determined at high resolution. The relaxation parameters and rotational correlation time of HGC determined by NMR are consistent with the monomeric state of the protein. While dipole moments have been calculated for several $\gamma$-crystallins, we find that they do not correlate with the solubility of HGC.

\section{EXPERIMENTAL PROCEDURES}

\section{Protein Expression, Purification, and Solubility Test for HGC}

cDNA for HGC cloned in the pET3a vector was a generous gift from N. Lubsen (Radboud University, Nijmegen, The Netherlands). Procedures for protein expression and purification were identical to those reported earlier for HGD. ${ }^{16}{ }^{15} \mathrm{~N}$ - and ${ }^{13} \mathrm{C}$-labeled proteins were prepared as described previously. ${ }^{22}$ This pure protein solution was extensively dialyzed against double-distilled water, and subsequently, $300 \mathrm{mg}$ of trehalose (Calbiochem) was dissolved in $15 \mathrm{~mL}$ of a $2 \mathrm{mg} / \mathrm{mL}$ dialyzed protein solution prior to lyophilization and storage at $-80{ }^{\circ} \mathrm{C}$. Trehalose was removed by extensive dialysis against the appropriate buffer prior to all experiments. Electrospray ionization mass spectroscopy analysis, performed at the University at Albany Proteomics Facility, gave a mass of $20746 \pm 1$ Da for different preparations of the wild-type protein that was found to be identical to the calculated mass (20747 Da).

For solubility tests, protein solutions were concentrated by ultrafiltration (Amicon, MerckMillipore Ltd.) with a MWCO of $10 \mathrm{kDa}$. Protein concentration was estimated using an extinction coefficient of $42860 \mathrm{M}^{-1} \mathrm{~cm}^{-1}$ (assuming all the Cys residues are reduced). On the basis of the observation that the protein could be concentrated to $200 \mathrm{mg} / \mathrm{mL}$ without precipitation, the solubility limit was estimated to be $200 \mathrm{mg} / \mathrm{mL}$ in $0.1 \mathrm{M}$ phosphate buffer $(\mathrm{pH} 7)$.

\section{Sample Preparation for NMR Measurements}

Purified and lyophilized ${ }^{15} \mathrm{~N}$-enriched or ${ }^{13} \mathrm{C}$ - and ${ }^{15} \mathrm{~N}$-enriched samples of $\mathrm{HGC}$ were dissolved in $20 \mathrm{mM}$ potassium phosphate buffer (pH 7.0) containing $20 \mathrm{mM} \mathrm{NaCl}, 5 \mathrm{mM}$ DTT, and $0.01 \% \mathrm{NaN}_{3}$. The protein samples were then dialyzed against a buffer of the same composition to remove trehalose and concentrated by ultrafiltration. Samples for NMR spectroscopy were prepared in a $90 \% \mathrm{H}_{2} \mathrm{O} / 10 \% \mathrm{D}_{2} \mathrm{O}$ solvent or $100 \% \mathrm{D}_{2} \mathrm{O}$ with the buffer composition described above. The reported $\mathrm{pH}$ is uncorrected for deuterium isotope effects. NMR data were recorded on samples that were $0.4-0.6 \mathrm{mM}$ in concentration.

\section{Data Acquisition}

Double- and triple-resonance NMR experiments for sequence-specific assignments, for obtaining distance restraints, for measurement of coupling constants, and for ${ }^{15} \mathrm{~N}$ relaxation rates were acquired on a Varian (Agilent) $600 \mathrm{MHz}$ spectrometer equipped with a $5 \mathrm{~mm}$ 
triple-resonance cold probe fitted with a single (Z-axis) pulsed field gradient accessory. Hydrogen-deuterium exchange experiments were performed on a Bruker Avance 700 NMR spectrometer, equipped with a cryoprobe fitted with a Z-axis only pulsed field gradient accessory. The sample temperature was maintained at $25{ }^{\circ} \mathrm{C}$ during all experiments. Onedimensional proton NMR spectra were acquired using the excitation sculpting solvent suppression scheme. ${ }^{23}$

Solvent suppression in two- and three-dimensional double- and triple-resonance experiments was achieved by using pulse programs that incorporated water flip-back pulses or flip-back pulses in combination with coherence selection via pulse field gradients. ${ }^{24}$ All spectra were recorded in phase sensitive mode. ${ }^{24}$

A list of the NMR experiments and the relevant data acquisition parameters are provided in Table S-1 of the Supporting Information. All spectra were referenced to an external DSS chemical shift standard.

\section{Data Processing and Analysis}

All two-dimensional (2D) and 3D NMR data were processed using NMRPipe/NMRDraw processing software ${ }^{25}$ on an Apple Macintosh system running the Mac OS X Yosemite system. Spectra were processed by applying a squared sine-bell weighting function that was phase shifted by $90^{\circ}$. Data sets were zero-filled once in each dimension to yield final matrices of $1024 \times 256 \times 128$ real data points. Spectra were analyzed using CCPNMR. ${ }^{26}$

\section{${ }^{15} \mathrm{~N}$ Backbone Dynamics}

Measurement of $\mathbf{T}_{\mathbf{1}}$ and $\mathbf{T}_{\mathbf{2}}$-The spin-lattice relaxation rate $\left(1 / T_{1}\right)$, and spin-spin relaxation rate $\left(1 / T_{2}\right)$ were measured by recording a series of two-dimensional ${ }^{1} \mathrm{H}_{-}{ }^{15} \mathrm{~N}$ HSQC spectra with different $T_{1}$ and $T_{2}$ relaxation delay time intervals. ${ }^{27}$ Each $t_{1}$ data time point was signal averaged over 32 transients. The data sets were acquired using the pulse schemes described by Farrow et al. ${ }^{27}$ The relaxation delays were set to 10, 50, 90, 130, 290, $410,550,700,850,1000$, and $1200 \mathrm{~ms}$ for measuring $T_{1}$ and 10, 30, 50, 70, 90, 110, 130, 150,170 , and $190 \mathrm{~ms}$ for measuring $T_{2}$. To permit the estimation of noise levels, duplicate spectra were recorded at delay points of $50 \mathrm{~ms}$ for measuring $T_{1}$ and $70 \mathrm{~ms}$ for measuring $T_{2}$. A delay of $1 \mathrm{~s}$ was introduced between transients to re-establish thermal equilibrium during these experiments. These spectra were acquired using the randomized order of $T_{1}$ and $T_{2}$ delay times.

Measurement of Steady-State Heteronuclear $\left\{{ }^{1} \mathrm{H}\right\}-{ }^{15}$ N NOEs-Two spectra were recorded to measure NOE values at the same temperature and magnetic field strength in the presence and absence of a proton presaturation period of 3 s, i.e., NOE and no-NOE, respectively. For the NOE spectrum, the relaxation delay, as well as saturation time period, was set to $3 \mathrm{~s}$. For the no-NOE spectrum, the relaxation delay was set to $3 \mathrm{~s}$ without saturation.

$T_{1}, T_{2}$, and $\left\{{ }^{1} \mathrm{H}\right\}-{ }^{15} \mathrm{~N}$ NOE values were determined by fitting peak heights using the nonlinear least-squares routine available in Analysis (version 2.4.2). 


\section{Hydrogen-Deuterium Exchange}

A lyophilized sample of $\mathrm{HGC}$ was dissolved in $100 \% \mathrm{D}_{2} \mathrm{O}$ just prior to data acquisition. A series of $2 \mathrm{D}{ }^{1} \mathrm{H}-{ }^{15} \mathrm{~N}$ HSQC spectra were acquired at intervals of 10 min over a period of 44 h.

\section{Structural Restraints}

Rotational Correlation Time $\left(\tau_{\mathrm{c}}\right)$-The rotational correlation time $\left(\tau_{\mathrm{c}}\right)$ was calculated using eq $1^{28}$

$$
\tau_{\mathrm{C}}=\frac{1}{2 \omega_{\mathrm{N}}} \sqrt{\frac{6 T_{1}}{T_{2}}-7}
$$

where $\omega_{\mathrm{N}}$ is the Larmor precessional frequency of the ${ }^{15} \mathrm{~N}$ nucleus.

Secondary Structure and Dihedral Angle Restraints-(I) The chemical shift index (CSI) was calculated using the CSI protocol established by Wishart and Skyes. ${ }^{29}$ $\mathrm{H}^{a},{ }^{13} \mathrm{C}^{a},{ }^{13} \mathrm{C}^{\beta}$, and ${ }^{13} \mathrm{C}^{\prime}$ chemical shifts were used to calculate CSI. (II) Backbone ${ }^{3} J_{\mathrm{HNH} a}$ coupling constants were calculated from the ratios of the intensities of the diagonal and cross-peaks in the 3D HNHA experiment. ${ }^{30}$ (III) Backbone dihedral angles $\Phi$ and $\Psi$ were predicted using DANGLE (which is provided with the CCPNMR ${ }^{26}$ suite of programs) from observed $\mathrm{H}^{\mathrm{N}},{ }^{1} \mathrm{H}^{a},{ }^{13} \mathrm{C}^{a},{ }^{13} \mathrm{C}^{\beta}$, and ${ }^{13} \mathrm{C}^{\prime}$ chemical shifts. (IV) Side-chain $\left(\chi_{1}\right)$ dihedral angle conformations and stereospecific assignments for the $\beta$-methylene protons were determined from correlations observed in the HNHB and HNCOHB spectra ${ }^{31}$

Distance Restraints and Tertiary Structure-(I) For NOEs, interproton distance restraints were calculated from the intensities of unambiguously assigned NOE correlations in the $3 \mathrm{D}{ }^{15} \mathrm{~N}$-edited NOESY-HSQC and ${ }^{13} \mathrm{C}$-edited NOESY-HSQC spectra. ${ }^{32,24}$ On the basis of integrated intensities, NOEs were classified as strong, medium, weak, and very weak with upper distance bounds of 2.8, 3.5, 5.0, and $6.0 \AA$, respectively. All distance restraints employed a lower bound of $1.80 \AA$. (II) For hydrogen bond restraints, hydrogendeuterium exchange experiments were conducted to identify backbone amide protons that could participate in hydrogen bonds. Amide protons that were slow to exchange ( $>1 \mathrm{~h}$ ) with bulk $\mathrm{D}_{2} \mathrm{O}$ solvent were considered to be buried or hydrogen bond donors. The upper distance bounds employed for the hydrogen bonds were set to $2.3 \AA$ for $\mathrm{NH} \cdots \mathrm{O}$ pairs and $3.3 \AA$ for $\mathrm{N} \cdots \mathrm{O}$ pairs.

\section{Solution Structure Calculation}

Structure Calculation and Refinement-Three-dimensional structures were calculated using the torsion angle dynamics protocol in CYANA version 3.0. ${ }^{33}$ NMR-derived dihedral angles and interatomic distances (NOE and hydrogen bond) were input as restraints for structure calculations. An angular variation $\left( \pm 30^{\circ}\right)$ in backbone dihedral angle was allowed during structure calculation. 
Two hundred random conformers were subjected to 20000 steps of annealing. Forty lowenergy conformers that had no upper distance violations of $>0.2 \AA$ or dihedral angle violations of $>5^{\circ}$ were selected for further analysis and refinement. The conformer with the minimal energy/target function was chosen as a representative conformer. The structures were analyzed using MOLMOL. ${ }^{34}$

Structural Refinement with Water-First, output files from CYANA were converted into the CNS format using pdbstat ${ }^{35}$ with a $10 \%$ range for the upper bound (upper limit for NOEs), and the van Der Waals radius was used as the lower bound (lower limit for NOEs). The refinement was conducted using $\mathrm{CNS}^{36}$ The protein structure validation suite (PSVS ${ }^{37}$ has been used to check the quality of the structure.

Comparison of HGC with Other Homologues-The structure of HGC determined here was compared with the experimentally determined structures of MGC and the closely related HGD and HGS structures. Structural alignment was performed using $\mathrm{DALI}^{38}$ and CHIMERA. ${ }^{39}$

\section{Calculation of Dipole Moments}

PDB files of all the $\gamma$-crystallin proteins used were first uploaded in the $\mathrm{H}++$ server, version 3.2 (http://biophysics.cs.vt.edu), which added hydrogens as well as charges at the specified $\mathrm{pH}$. The dielectric model for predicting the protonation states of ionizable residues in proteins is based on the work of Bashford and Karplus. ${ }^{40}$ The protein internal and external dielectric constants and salinity ( $0.15 \mathrm{M}$ monovalent salt) were set at their default values of 10,80 , and 0.15 , respectively. The structures thus produced from this server were then uploaded into Chimera version 1.10.2 to calculate dipole moments according to the method of Felder et al. ${ }^{41}$ This method of computing dipole moments is essentially consistent with that used by Mellor et al. ${ }^{42}$ For a given protein, the magnitude and direction of the dipole moment are calculated as the vector sum of the dipole moments of the core (i.e., the peptide chain) and the side chains. The origin of the arrow representing the dipole moment vector is the center of mass of the protein, with the length representing the scaled magnitude. The arrow is conventionally drawn from the negative charge toward the positive charge.

\section{RESULTS AND DISCUSSION}

\section{Solubility Properties of HGC}

We state at the outset that we were able to prepare solutions of HGC at concentrations of up to $200 \mathrm{mg} / \mathrm{mL}$ when it is dissolved in phosphate buffer ( $\mathrm{pH} 7)$. Our results contradict those of Slingsby and co-workers, ${ }^{20}$ who reported that HGC was poorly soluble $(<2 \mathrm{mg} / \mathrm{mL})$, but are in agreement with those of other laboratories that have studied $\mathrm{HGC},{ }^{43,44}$ and we did not find any difficulty in solubilizing HGC in aqueous buffers. Although a cataract-associated mutant, T4P of HGC, does exhibit decreased solubility, which has been suggested to be the molecular basis of the Coppock-like cataract mutation, ${ }^{43}$ it can be argued that the protocols employed by $\mathrm{Fu}$ and Liang ${ }^{43}$ did not require high protein concentrations for which solubility would be a significant issue. Hence, these studies may not be true indicators of solubility. In contrast, high protein concentrations are in fact needed for structure determination at atomic 
resolution by either X-ray crystallography (attempted by Slingsby and co-workers) or NMR spectroscopy (this study). Thus, to obtain an unambiguous assessment of protein solubility, we expressed five different batches of HGC and conducted the purification and mass spectrometric analyses of each batch to ensure that we had the pure protein, before producing the labeled proteins. Each of our preparations could be consistently concentrated to $200 \mathrm{mg} / \mathrm{mL}$ without any aggregation or precipitation. We note that our method of isolation and purification of HGC differs from the various methods used by Purkiss et al. ${ }^{20}$, but it is difficult to identify any key step that could have led to the significant differences in protein solubility observed in the two cases. Our goal here is to report that HGC appears to be a typical member of the crystallin family with a high solubility that is consistent with those of other crystallins in the lens. Such "normal" protein solubility allowed us to conduct the NMR experiments presented here in a facile manner.

\section{Solution Structure Determination}

The one- and two-dimensional, proton and ${ }^{1} \mathrm{H}-{ }^{15} \mathrm{~N}$ HSQC NMR spectra of HGC (Figures S-1 and S-2, respectively) show well-resolved and well-dispersed resonances with narrow line widths in the amide proton and amide nitrogen region, indicating that the molecule tumbles isotropically in solution. The number of correlation peaks in the $2 \mathrm{D}^{1} \mathrm{H}-{ }^{15} \mathrm{~N}$ HSQC spectrum is 197, which agrees well with the expected number of 200 for HGC.

Sequence-Specific Assignments and Secondary Structure-The sequencespecifically assigned ${ }^{1} \mathrm{H}-{ }^{15} \mathrm{~N}$ HSQC spectrum of HGC is shown in Figure 1. Resonance assignments of backbone and side-chain ${ }^{1} \mathrm{H},{ }^{13} \mathrm{C}$, and ${ }^{15} \mathrm{~N}$ nuclei were made from an analysis of corroborative evidence available in multiple double- and triple-resonance NMR data sets. ${ }^{24,45,46}$ Sequence-specific assignments of HGC posed several challenges, because of the nature of the primary structure of the protein. HGC is composed of two structural domains that show $\sim 40 \%$ sequence identity (Figure S-3). Two sections of the protein, i.e., Gly ${ }^{40}-\mathrm{Trp}^{68}$ in the $\mathrm{N}$-terminal domain and Cys ${ }^{128}{ }^{-T_{r}}{ }^{156}$ in the C-terminal domain, have $66 \%$ identical sequences. Within this, residues 54-58 and 142-146 are identical (the probability of a five-residue repeat in a protein $<200$ amino acids in length is $\ll 1 \%) .{ }^{47}$ Figure 2 shows the sequence-specific assignments for residues 54-58 and 142-146 in the 3D $\mathrm{HNCACB}^{48}$ (panels I and II) and CC(CO)NNH-TOCSY ${ }^{49}$ (panels III and IV) spectra, respectively. Despite the $100 \%$ sequence identity in both these stretches, good dispersion in one or more of the frequency dimensions in the triple-resonance data sets allowed the sequence-specific assignments to be made in a facile manner.

The chemical shifts of the $\mathrm{C}^{\beta}$ atoms of the cysteine residues clearly indicate that the cysteines are in the reduced state. ${ }^{50}$ Mass spectrometric analysis of alkylated HGC shows that five of the eight cysteines are readily alkylated in the absence of any reducing agent (Figure S-4 of the Supporting Information). Surface accessibility calculations ${ }^{51}$ show that $\mathrm{Cys}^{32}$ and $\mathrm{Cys}^{78}$ are buried while Cys ${ }^{79}$ and Cys ${ }^{108}$ are partially buried and almost equally accessible. Taken together, these observations suggest that cysteines 32 and 78 and one of the two, viz., 79 or 108, are inaccessible for the alkylation reaction. We discuss later in this section the possibility that, in fact, $\mathrm{Cys}^{79}$ may not be available for alkylation because of an ion-pair interaction. 
Secondary Structure-The secondary structure, computed from ${ }^{1} \mathrm{H}^{a},{ }^{13} \mathrm{C}^{a},{ }^{13} \mathrm{C}^{\beta}$, and ${ }^{13} \mathrm{C}^{\prime}$ chemical shifts (CSI), sequential and short-range NOEs, and backbone ${ }^{3} J_{\mathrm{HNH} a}$ coupling constants (Figure 3), showed that HGC consists of $11 \beta$-strands, $4 \beta$-hairpins, and 1 one-turn helix. Approximately $60 \%$ of the residues are present in regular secondary structural elements. The remainder of the residues occur in loop/flexible regions.

${ }^{15} \mathrm{~N}$ Backbone Dynamics-The $T_{1}, T_{2}$, and heteronuclear NOE values were measured for the backbone ${ }^{15} \mathrm{~N}$ nuclei (Figure 4) of HGC. Data for several of the residues and the time constants calculated by curve fitting are shown in Figure S-5 of the Supporting Information. From the average values of $T_{1}$ and $T_{2}$, the overall rotational correlational time was calculated using eq $1^{28}$ and was found to be $\sim 10.9 \mathrm{~ns}$. This value correlates well with the value expected for a monomeric $21 \mathrm{kDa}$ protein. Thus, there is no evidence of intermolecular interactions. From the resonance assignments, it is also clear that the molecule does not exhibit conformational heterogeneity and that a single isotropically tumbling species of HGC exists in solution.

\section{Structural Restraints}

NOEs: Through-space correlations between pairs of dipolar coupled protons were observed in the $3 \mathrm{D}{ }^{13} \mathrm{C}$ - and/or ${ }^{15} \mathrm{~N}$-edited NOESY-HSQC spectra $\left(\tau_{\mathrm{m}}=125 \mathrm{~ms}\right) .{ }^{32}$ Spectra were manually assigned by visual comparison with correlations observed in scalar coupled $3 \mathrm{D}{ }^{13} \mathrm{C}$ - and ${ }^{15} \mathrm{~N}$-edited proton-proton correlated spectra. Figure 5 shows the interstrand NOEs that define the sheet topology in the N-and C-terminal domains of HGC. Figure 6 shows in strip plot format, the sequence-specific assignments for residues that are involved in domain-domain interactions, i.e., 54, 56, 142, 144 ( $\beta 5$ and $\beta 12$ ), and 112-117 ( $a$-helix). A total of 1960 unambiguous NOE correlations were assigned. The numbers of long-range (| $i-\lambda \mid \geq 5)$ and medium-range $(1 \leq \mid i-\lambda)$ NOE correlations were 30 and $40 \%$, respectively, of the number of assigned correlations. The details of these restraints are listed in Table 1. An inter-residue contact map showing the density of NOEs as a function of sequence is shown in Figure S-6 of the Supporting Information. Assignment of sequential, short-range, and medium-range NOEs provided corroborative evidence of the secondary structure determined from ${ }^{1} \mathrm{H},{ }^{13} \mathrm{C}^{a}$, and ${ }^{13} \mathrm{C}^{\beta}$ secondary chemical shifts.

Hydrogen Bonds-The H/D exchange time constants for the backbone amide protons are indicated in Figure 3. Residues that were identified to be present in $\beta$-strands also had amide protons that were slow to exchange ( $>10 \mathrm{~h}$ ), indicating that these protons either are involved in hydrogen bonding interactions or are buried in the interior of the protein. Indeed, 66 amide protons were not exchanged even after 24 days (Figure S-7 of the Supporting Information).

Dihedral Angle Restraints-Backbone dihedral angles ( $\varphi$ and $\psi$ ) were predicted using DANGLE. ${ }^{26}$ A total of $163 \varphi$ and $163 \psi$ angles were predicted. The predicted dihedral angles were validated with secondary structural information obtained from ${ }^{3} J_{\mathrm{HNH} a}$ coupling constants and sequential NOEs. The $\chi_{1}$ angle restraints for side chains of 110 residues were determined from an analysis of the complementary $\mathrm{HNHB}$ and $\mathrm{HN}(\mathrm{CO}) \mathrm{HB}$ spectra according to the methods of Bax et al. ${ }^{31}$ and Wagner et al. ${ }^{52}$ Of these, 20, 26, and 64 
residues were found to have side chains in the $\mathrm{g}^{2} \mathrm{~g}^{3}, \mathrm{~g}^{2} \mathrm{t}^{3}$, and $\mathrm{t}^{2} \mathrm{~g}^{3}$ conformations, respectively.

Three-Dimensional Structure-The three-dimensional structure of HGC was determined using NMR-derived distance, dihedral, and hydrogen bond restraints. Initial rounds of structure calculations were performed with distance and dihedral angle restraints only. Hydrogen bond restraints were introduced during the later stages of structure calculations. The details of the number and type of restraints used for structure calculation are listed in Table 1. Table 1 also lists the structural parameters derived for the ensemble of low-energy structures. A superposition of the 20 lowest-energy conformers is shown in Figure 7A. The lowest-energy structure is shown in a ribbon representation (Figure 7B). The rmsd values, when the structures are superposed on the backbone $\left(\mathrm{N}, \mathrm{C}^{a}\right.$, and $\left.\mathrm{C}^{\prime}\right)$ atoms and on all heavy atoms with respect to their mean coordinate position, were $0.60 \pm 0.12$ and 1.03 $\pm 0.09 \AA$, respectively. The high percentages of backbone dihedral angles in the most favored and additionally allowed regions ( 82 and $18 \%$, respectively) of the Ramachandran map indicate that the ensemble structures are of good stereochemical quality. ${ }^{53}$

\section{Tertiary Structure}

The structure of HGC is formed from two domains, each of which has one Greek-key motif and one three-stranded antiparallel $\beta$-sheet. Thus, the two domains are structurally similar. The Greek-key motifs (labeled as $\mathrm{A}$ and $\mathrm{C}$ in the $\mathrm{N}$ - and $\mathrm{C}$-terminal domains, respectively) classically consist of the four-antiparallel $\beta$-strand arrangement. Motif $\mathrm{A}$ is constructed from the $\beta$-strands $\beta 1-\beta 3$ and $\beta 6$, while motif $\mathrm{C}$ is constructed from $\beta$-strands $\beta 8-\beta 10$ and $\beta 13$. The three-stranded $\beta$-sheets (labeled as B and D in each domain) are constructed from strands $\beta 4, \beta 5$, and $\beta 7$ and strands $\beta 11, \beta 12$, and $\beta 14$, respectively. $\beta$-Sheets $\mathrm{B}$ and $\mathrm{D}$ structurally resemble the Greek-key motifs ${ }^{54}$ and could still be classified as Greek-key motifs despite the absence of the regular fourth $\beta$-strand. The antiparallel arrangement of the strands in the Greek-key motifs and in $\beta$-sheets $\mathrm{B}$ and $\mathrm{D}$ is best understood from the manifestation of the cross-strand NOEs between residues in the juxtaposed strands (Figure $5 \mathrm{~A}, \mathrm{~B})$. If one were to use the classification proposed by Hutchinson and Thronton, ${ }^{55}$ the Greek-key motifs in HGC and in the $\beta$-crystallins could be classified as $(3,1)_{\mathrm{c}}$. The HGC has the same sheet topology that has been observed for the $\beta$-crystallins. However, $\beta$-crystallins are known to exist as dimers, ${ }^{56}$ and this dimerization occurs through domain swapping to achieve the sheet topology observed in the monomeric $\gamma$-crystallins.

The interdomain interface is formed by residues in strands $5(54 \mathrm{Q}-58 \mathrm{R})$ and 12 (142Q146R). Interestingly, the residues in these two strands are the repeat sequences mentioned above. Thirteen long-range NOEs, of which eight were unambiguously assigned as sidechain to backbone amide proton NOEs, were crucial in determining the orientation of the individual domains. Furthermore, the amide protons in residues 54, 56, and 58 and residues 142,144 , and 146, which point toward the interface, are significantly slow to exchange in $\mathrm{H} / \mathrm{D}$ exchange experiments (Figure 3). In the absence of a buried interdomain interface, the amide protons at the interface would have exchanged rapidly because of solvent exposure. There is another important observation to be made here: R146 points into the domain 
interface, and not "away from the N-terminal domain (into space)" as reported in the model of HGC. ${ }^{20}$

Accessible surface area calculations show that these residues have solvent accessibilities of $3.2,1.2$, and $20.0 \%$ and $8.1,6.8$, and $37.3 \%$, respectively. The interface domain covers an area of $1942 \AA^{2}$, indicative of significant structural stabilization through interdomain interactions.

The solvent accessible surface area calculations also indicate good packing within the core of the protein molecule. NMR relaxation parameters $T_{1}, T_{2}$, and heteronuclear NOE are uniform for almost all the residues in HGC. Furthermore, >95\% of the residues have heteronuclear NOE values of $>0.8$, indicating that the molecule is rigid.

\section{Comparison of HGC with Other $\gamma$-Crystallins}

Prior to this study, the only structure of a $\chi$ C-crystallin available was that of MGC (PDB entry $2 \mathrm{v} 2 \mathrm{u}$ ). The human ortholog has a sequence $84 \%$ identical to that of the mouse protein, whose structure has been determined by X-ray crystallography. ${ }^{20}$ With the exception of Pro $^{27} \mathrm{Thr}$, Val ${ }^{85} \mathrm{Gly}$, and Pro ${ }^{109} \mathrm{Ser}$, the other replacements in the mouse protein are of a conservative nature. For instance, $\mathrm{Gln}^{53}$ and $\mathrm{Gln}^{83}$ are replaced with histidine in the mouse sequence. Similarly, $\mathrm{Gln}^{53}, \mathrm{Gln}^{83}$, and $\mathrm{Gln}^{154}$ are all replaced with histidine in the rat sequence. $\operatorname{Pro}^{27}, \mathrm{Gln}^{53}$, Val ${ }^{85}$, $\mathrm{Pro}^{109}$, and $\mathrm{Gln}^{154}$ are all surface-exposed residues, with $\mathrm{Gln}^{83}$ and $\mathrm{Val}^{85}$ occurring at the center of the bridge that connects the two domains.

None of these residues occurs in regular secondary structural elements in the proteins. When superposed on backbone $\mathrm{N}, \mathrm{C}^{a}$, and $\mathrm{C}^{\prime}$ atoms, the structures of HGC and MGC (Figure S-8) show an rmsd of $1.3 \AA$. These two proteins have calculated pI values of 7.0 and 7.7, respectively. Calculation of surface charge potentials shows that the two proteins have nearly identical surface charge distributions (Figure S-9). Importantly, the molecules are devoid of large or significant areas of hydrophobic surfaces, which minimizes the propensity for aggregation. A comparison of the distribution of secondary structural elements in the structures determined by NMR spectroscopy (HGC) and X-ray (MGC) is given in Table S-2 of the Supporting Information.

Purkiss et al. ${ }^{20}$ have argued that the presence of a cysteine at position 79 in the human protein, as compared to an arginine at the identical position in the mouse protein, lowers the electrostatic potential in this region, thereby promoting self-association leading to the anomalous or unprecedented low solubility of HGC. How this leads to aggregation and low solubility is unclear. In the structures determined here, we observe that $\mathrm{Cys}^{79}$ lies at the interdomain interface (ASA of 11.9\%). In addition, Asp $^{21}$ (ASA of 49.8\%) is present in the proximity of $\mathrm{Cys}^{79}$. Furthermore, the side chain of $\operatorname{Arg}^{146}$ (ASA 37.3), from across the interdomain interface, is also proximal to the side chain of $\mathrm{Asp}^{21}$. Although side-chain definitions in the NMR structures determined here are at low resolution due to a lack of restraints, the possibility of ion-pair interactions between $\mathrm{Asp}^{21}$ and $\mathrm{Arg}^{146}$ or $\mathrm{Cys}^{79}$ and $\operatorname{Arg}^{146}$ exists. 
Platzer and co-workers ${ }^{57}$ have shown that the ${ }^{13} \mathrm{C}^{\beta}$ chemical shift of cysteine is $\sim 28 \mathrm{ppm}$ for the thiol and $29.7 \mathrm{ppm}$ for the thiolate. We have observed that the ${ }^{13} \mathrm{C}^{\beta}$ atom of Cys ${ }^{79}$ exhibits a chemical shift of $31.4 \mathrm{ppm}$. This strongly suggests that $\mathrm{Cys}^{79}$ may be present in the thiolate form, which could participate in ion-pair interactions with $\mathrm{Arg}^{146}$. However, it must be stressed that at the current resolution we do not have definitive proof of this.

Purkiss et al. ${ }^{20}$ have calculated $\mathrm{C}^{\beta}-\mathrm{C}^{\beta}$ distances (angstroms) for the three residue pairs across the domain-domain interface during the $5 \mathrm{~ns}$ MD simulation trajectory for their HGC model, and the X-ray structures of MGC and HGD. Their main argument is that because of the $\mathrm{Leu}^{56}$ residue in $\mathrm{HGC}$, as opposed to the Phe ${ }^{56}$ residue in HGD and MGC, the residuepair distances (representing interdomain distances) are larger in the HGC model than in MGC and HGD, resulting in a more open and less rigid interface, leading to largermagnitude fluctuations, as observed in the MD simulations. We find that the residue-pair distances in the NMR structure of HGC (in bold) are closer to those for HGD and MGC than those for the modeled HGC structure (shown in Table 2).

\section{Dipole Moments}

We have calculated the overall dipole moment for HGC [NMR structure 1 (Figure 8)] and the orientation of this dipole moment, which is similar to that shown for HGD by Purkiss et al., ${ }^{20}$ but unlike that of their model of HGC. Our calculated value for the magnitude of the overall dipole moment for HGC is $274.4 \mathrm{D}$, which is closer to that of the mouse protein, MGC (209.8 D), rather than that for the model of HGC (134.4 D) reported in the same study.

When the mean overall dipole moment of the HGC model $\left(134.4 \mathrm{D}^{20}\right)$ is compared with that of R36S (346.1 D), a cataract-associated mutant of HGD known for its low solubility, ${ }^{9}$ it is found that these values are significantly different from the dipole moments of other $\gamma$ crystallins, all of which fall in the range of 204-231 D. Normally, a low magnitude of the dipole moment describes a symmetric distribution of charges and vice versa. ${ }^{58} \mathrm{It}$ is, therefore, puzzling how values of the dipole moment that are lower (HGC) or higher (R36S) than the "normal" (204-231 D) could both lead to lowered protein solubility as Purkiss et al. ${ }^{20}$ conclude.

In Figure 9A, we show the peptide backbone of the N-terminal domain (residues 1-83) of HGC (in red) and the corresponding computed dipole moment for this domain. We note that for the computation of the dipole moment, both the peptide backbone and side chains were included. Also shown in the figure are the N-terminal domain of MGC (in blue) (PDB entry $2 \mathrm{v} 2 \mathrm{u}$ ) and its corresponding dipole moment. The dipole moments of chains A and B are 139.2 and 126.7 D, respectively, and that of the corresponding human protein is $61.3 \mathrm{D}$. These magnitudes of dipole moments are remarkably close to those reported by Purkiss et al. ${ }^{20}$ namely, 139.4 and 57.6 D for the mouse and human proteins, respectively. However, the orientations appear to differ. In Figure 9B, we have computed the dipole moment of bovine $\gamma \mathrm{B}$-crystallin (BGB, PDB entry $4 \mathrm{gcr}$ ), a highly soluble protein, ${ }^{3}$ in the same manner that was used for the others, and displayed similarly, and find that its magnitude $(88 \mathrm{D})$ is also low. Thus, the low magnitude of the dipole moment of the $\mathrm{N}$-terminal domain does not appear to be unusual. 
From the results of their molecular dynamics study, Purkiss et al. ${ }^{20}$ point out that the dipole moment of the N-terminal domain in HGC undergoes the largest variation (range of 3-106 D); however, from their own work, the N-terminal domains of the other $\gamma$-crystallins, for example, MGC, also show almost a similar variation of $>100 \mathrm{D}$, between the minimal and maximal values. These authors have also attributed the small magnitude and high variability of the dipole moment of the N-terminal domain of the HGC model to the insolubility of the protein. However, our observations taken together with the NMR dynamics data (Figure 4), and the rotational correlation time, rule out any short-range attractive interactions arising from such variability in the dipole moment that could explain the low protein solubility reported by these authors. Thus, we conclude that the magnitude and direction of the dipole moments of the whole protein, or the individual domains in the $\gamma$-crystallins, are not a good measure of their solubility.

\section{CONCLUSIONS}

We have presented a detailed NMR solution structure of HGC, which is the only major human $\gamma$-crystallin whose 3D structure is not available. We observed distinct, although subtle, differences in the orientation of certain side chains (e.g., $\operatorname{Arg}^{146}$ ), and in the packing of the domain interface, compared to those of a structural model, based on the mouse ortholog, reported previously. ${ }^{20}$ Our major finding is that HGC is as soluble as other crystallins, which contradicts the earlier study. ${ }^{20}$ No evidence of short-range intermolecular interactions was observed, which would hinder free tumbling of the monomeric protein in solution. Such interactions were suspected ${ }^{20}$ on the basis of the fluctuations of the dipole moment in a molecular dynamics study of a model of HGC. The structure reported here will allow us to better understand the perturbations due to mutations, especially those associated with cataract. Thus, the solution structure of HGC is likely to play an important role in understanding the molecular basis of cataract. ${ }^{59}$ Our future studies will focus on the experimental determination of the complete phase diagram, including crystal solubility (i.e., the liquidus line $)^{9}$ and the magnitude of the dipole moment ${ }^{58}$ of HGC.

\section{Supplementary Material}

Refer to Web version on PubMed Central for supplementary material.

\section{Acknowledgments}

K.D. thanks the Council for Scientific and Industrial Research for a Senior Research Fellowship. S.P.S. thanks DBT and DST for the NMR facilities at the Indian Institute of Science. Work in the Pande lab is supported by Grant EY010535 from the National Institutes of Health.

\section{ABBREVIATIONS}

$\begin{array}{ll}\text { BGB } & \text { bovine } \gamma \mathrm{B} \text {-crystallin } \\ \text { HGC } & \text { human } \gamma \text { C-crystallin } \\ \text { HGD } & \text { human } \gamma \text { D-crystallin } \\ \text { HGS } & \text { human } \gamma \text { S-crystallin }\end{array}$




$\begin{array}{ll}\text { IPTG } & \text { isopropyl } \beta \text {-D-1-thiogalactopyranoside } \\ \text { MD } & \text { molecular dynamics } \\ \text { MGC } & \text { mouse } \gamma \text { C-crystallin } \\ \text { MWCO } & \text { molecular weight cutoff } \\ \text { NOESY } & \text { nuclear Overhauser effect spectroscopy } \\ \text { NMR } & \text { nuclear magnetic resonance spectroscopy } \\ \text { PDB } & \text { Protein Data Bank } \\ \text { rmsd } & \text { root-mean-square deviation } \\ \boldsymbol{\tau}_{\mathbf{c}} & \text { rotational correlation time } \\ \boldsymbol{\tau}_{\mathbf{m}} & \text { mixing time } \\ \boldsymbol{T}_{\mathbf{1}} & \text { spin-lattice relaxation time constant } \\ \boldsymbol{T}_{\mathbf{2}} & \text { spin-spin relaxation time constant }\end{array}$

\section{References}

1. Fagerholm PP, Philipson BT, Lindström B. Normal human lens - the distribution of protein. Exp Eye Res. 1981; 33:615-620. [PubMed: 7318958]

2. Berland CR, Thurston GM, Kondo M, Broide ML, Pande J, Ogun O, Benedek GB. Solid-liquid phase boundaries of lens protein solutions. Proc Natl Acad Sci U S A. 1992; 89:1214-8. [PubMed: 1741375]

3. Broide ML, Berland CR, Pande J, Ogun OO, Benedek GB. Binary-Liquid Phase-Separation of Lens Protein Solutions. Proc Natl Acad Sci U S A. 1991; 88:5660-5664. [PubMed: 2062844]

4. Zhao H, Brown PH, Magone MT, Schuck P. The molecular refractive function of lens $\gamma$-crystallins. J Mol Biol. 2011; 411:680-699. [PubMed: 21684289]

5. Siezen RJ, Thomson Ja, Kaplan ED, Benedek GB. Human lens gamma-crystallins: isolation, identification, and characterization of the expressed gene products. Proc Natl Acad Sci U S A. 1987; 84:6088-6092. [PubMed: 3476929]

6. Brakenhoff RH, Aarts HJ, Reek FH, Lubsen NH, Schoenmakers JG. Human gamma-Crystallin genes. A gene family on its way to extinction. J Mol Biol. 1990; 216:519-532. [PubMed: 2258929]

7. Lampi KJ, Ma Z, Shih M, Shearer TR, Smith JB, Smith DL, David LL. Sequence analysis of betaA3, betaB3, and betaA4 crystallins completes the identification of the major proteins in young human lens. J Biol Chem. 1997; 272:2268-2275. [PubMed: 8999933]

8. Kmoch S, Brynda J, Asfaw B, Bezouska K, Novak P, Rezacova P, Ondrova L, Filipec M, Sedlacek J, Elleder M. Link between a novel human gamma D-Crystallin allele and a unique cataract phenotype explained by protein crystallography. Hum Mol Genet. 2000; 9:1779-1786. [PubMed: 10915766]

9. Pande A, Pande J, Asherie N, Lomakin A, Ogun O, King J, Benedek GB. Crystal cataracts: human genetic cataract caused by protein crystallization. Proc Natl Acad Sci U S A. 2001; 98:6116-6120. [PubMed: 11371638]

10. Banerjee PR, Pande A, Patrosz J, Thurston GM, Pande J. Cataract-associated mutant E107A of human $\gamma \mathrm{D}$-Crystallin shows increased attraction to $a$-Crystallin and enhanced light scattering. Proc Natl Acad Sci U S A. 2011; 108:574-579. [PubMed: 21173272]

11. Banerjee PR, Puttamadappa SS, Pande A, Shekhtman A, Pande J. Increased hydrophobicity and decreased backbone flexibility explain the lower solubility of a cataract-linked mutant of $\gamma \mathrm{D}$ Crystallin. J Mol Biol. 2011; 412:647-659. [PubMed: 21827768] 
12. Ji F, Jung J, Gronenborn AM. Structural and biochemical characterization of the childhood cataract-associated R76S mutant of human $\gamma$ D-Crystallin. Biochemistry. 2012; 51:2588-2596. [PubMed: 22394327]

13. Lee S, Mahler B, Toward J, Jones B, Wyatt K, Dong L, Wistow G, Wu Z. A single destabilizing mutation (F9S) promotes concerted unfolding of an entire globular domain in $\gamma \mathbf{S}$-Crystallin. J Mol Biol. 2010; 399:320-330. [PubMed: 20382156]

14. Pande A, Annunziata O, Asherie N, Ogun O, Benedek GB, Pande J. Decrease in protein solubility and cataract formation caused by the Pro23 to Thr mutation in human $\gamma D$-Crystallin. Biochemistry. 2005; 44:2491-2500. [PubMed: 15709761]

15. Lim JC, Umapathy A, Donaldson PJ. Tools to fight the cataract epidemic: A review of experimental animal models that mimic age related nuclear cataract. Exp Eye Res. 2016; 145:432443. [PubMed: 26391448]

16. Pande A, Pande J, Asherie N, Lomakin A, Ogun O, King JA, Lubsen NH, Walton D, Benedek GB. Molecular basis of a progressive juvenile-onset hereditary cataract. Proc Natl Acad Sci U S A. 2000; 97:1993-1998. [PubMed: 10688888]

17. Basak A, Bateman O, Slingsby C, Pande A, Asherie N, Ogun O, Benedek GB, Pande J. Highresolution X-ray crystal structures of human $\gamma \mathrm{D}$ Crystallin $(1.25 \AA)$ and the R58H mutant $(1.15 \AA)$ associated with aculeiform cataract. J Mol Biol. 2003; 328:1137-1147. [PubMed: 12729747]

18. Kingsley CN, Brubaker WD, Markovic S, Diehl A, Brindley AJ, Oschkinat H, Martin RW. Preferential and specific binding of human $a \mathrm{~B}$-Crystallin to a cataract-related variant of $\gamma \mathrm{s}-$ Crystallin. Structure. 2013; 21:2221-2227. [PubMed: 24183572]

19. Ma Z, Piszczek G, Wingfield PT, Sergeev YV, Hejtmancik JF. The G18V CRYGS mutation associated with human cataracts increases $\gamma \mathrm{S}$-Crystallin sensitivity to thermal and chemical stress. Biochemistry. 2009; 48:7334-7341. [PubMed: 19558189]

20. Purkiss AG, Bateman Oa, Wyatt K, Wilmarth Pa, David LL, Wistow GJ, Slingsby C. Biophysical Properties of $\gamma \mathrm{C}$-Crystallin in Human and Mouse Eye Lens: The Role of Molecular Dipoles. $\mathrm{J}$ Mol Biol. 2007; 372:205-222. [PubMed: 17659303]

21. Liu B-F, Song S, Hanson M, Liang JJ-N. Protein-protein interactions involving congenital cataract T5P gammaC-Crystallin mutant: a confocal fluorescence microscopy study. Exp Eye Res. 2008; 87:515-20. [PubMed: 18926820]

22. Pande A, Zhang J, Banerjee PR, Puttamadappa SS, Shekhtman A, Pande J. NMR study of the cataract-linked P23T mutant of human $\gamma \mathrm{D}$-Crystallin shows minor changes in hydrophobic patches that reflect its retrograde solubility. Biochem Biophys Res Commun. 2009; 382:196-199. [PubMed: 19275895]

23. Hwang TL, Shaka AJ. Water Suppression That Works. Excitation Sculpting Using Arbitrary WaveForms and Pulsed-Field Gradients. J Magn Reson, Ser A. 1995; 112:275-279.

24. Palmer, AG., III, Fairbrother, WJ., Cavanagh, J., Skelton, NJ., Rance, M. Protein NMR Spectroscopy: Principles and Practice. 2. Acedemic Press; Amsterdam: 2007.

25. Delaglio F, Grzesiek S, Vuister G, Zhu G, Pfeifer J, Bax A. NMRPipe: A multidimensional spectral processing system based on UNIX pipes. J Biomol NMR. 1995; 6:277-293. [PubMed: 8520220]

26. Vranken WF, Boucher W, Stevens TJ, Fogh RH, Pajon A, Llinas M, Ulrich EL, Markley JL, Ionides J, Laue ED. The CCPN data model for NMR spectroscopy: development of a software pipeline. Proteins: Struct, Funct, Genet. 2005; 59:687-96. [PubMed: 15815974]

27. Farrow NA, Muhandiram R, Singer AU, Pascal SM, Kay CM, Gish G, Shoelson SE, Pawson T, Forman-Kay JD, Kay LE. Backbone Dynamics of a Free and a Phosphopeptide-Complexed Src Homology 2 Domain Studied by 15N NMR Relaxation. Biochemistry. 1994; 33:5984-6003. [PubMed: 7514039]

28. Fushman D, Xu R, Cowburn D. Direct determination of changes of interdomain orientation on ligation: Use of the orientational dependence of 15N NMR relaxation in $\mathrm{Abl} \mathrm{SH}(32)$. Biochemistry. 1999; 38:10225-10230. [PubMed: 10441115]

29. Wishart DS, Sykes BD. The ${ }^{13} \mathrm{C}$ chemical-shift index: a simple method for the identification of protein secondary structure using ${ }^{13} \mathrm{C}$ chemical-shift data. J Biomol NMR. 1994; 4:171-180. [PubMed: 8019132] 
30. Vuister GW, Bax A. Quantitative J correlation: a new approach for measuring homonuclear threebond J(HNH.alpha.) coupling constants in ${ }^{15} \mathrm{~N}$-enriched proteins. J Am Chem Soc. 1993; 115:7772-7777.

31. Bax A, Vuister GW, Grzesiek S, Delaglio F, Wang AC, Tschudin R, Zhu G. Measurement of Homo- and Heteronuclear J Couplings from Quantitative J Correlation. Methods Enzymol. 1994; 239:79-105. [PubMed: 7830604]

32. Marion D, Kay LE, Sparks SW, Torchia Da, Bax A. Three-dimensional heteronuclear NMR of nitrogen-15 labeled proteins. J Am Chem Soc. 1989; 111:1515-1517.

33. Güntert P. Structure calculation of biological macromolecules from NMR data. Q Rev Biophys. 1998; 31:145-237. [PubMed: 9794034]

34. Koradi R, Billeter M, Wüthrich K. MOLMOL: A program for display and analysis of macromolecular structures. J Mol Graphics. 1996; 14:51-55.

35. Tejero R, Snyder D, Mao B, Aramini JM, Montelione GT. PDBStat: a universal restraint converter and restraint analysis software package for protein NMR. J Biomol NMR. 2013; 56:337-351. [PubMed: 23897031]

36. Brünger AT, Adams PD, Clore GM, DeLano WL, Gros P, Grosse-Kunstleve RW, Jiang JS, Kuszewski J, Nilges M, Pannu NS, Read RJ, Rice LM, Simonson T, Warren GL. Crystallography \& NMR system: A new software suite for macro-molecular structure determination. Acta Crystallogr, Sect D: Biol Crystallogr. 1998; 54:905-921. [PubMed: 9757107]

37. Bhattacharya A, Tejero R, Montelione GT. Evaluating protein structures determined by structural genomics consortia. Proteins: Struct, Funct, Genet. 2007; 66:778-795. [PubMed: 17186527]

38. Holm L, Rosenström P. Dali server: conservation mapping in 3D. Nucleic Acids Res. 2010; 38:W545-W549. [PubMed: 20457744]

39. Pettersen EF, Goddard TD, Huang CC, Couch GS, Greenblatt DM, Meng EC, Ferrin TE. UCSF Chimera-a visualization system for exploratory research and analysis. J Comput Chem. 2004; 25:1605-1612. [PubMed: 15264254]

40. Bashford D, Karplus M. pKa's of ionizable groups in proteins: atomic detail from a continuum electrostatic model. Biochemistry. 1990; 29:10219-10225. [PubMed: 2271649]

41. Felder CE, Prilusky J, Silman I, Sussman JL. A server and database for dipole moments of proteins. Nucleic Acids Res. 2007; 35:W512-W521. [PubMed: 17526523]

42. Mellor B, Cruz Cortés E, Busath DD, Mazzeo BA. Method for estimating the internal permittivity of proteins using dielectric spectroscopy. J Phys Chem B. 2011; 115:2205-2213. [PubMed: 21344910]

43. Fu L, Liang JJN. Conformational change and destabilization of cataract $\gamma$ C-Crystallin T5P mutant. FEBS Lett. 2002; 513:213-216. [PubMed: 11904153]

44. Acosta-Sampson L, King J. Partially Folded Aggregation Intermediates of Human $\gamma \mathrm{D}-, \gamma \mathrm{C}$-, and $\gamma \mathrm{S}$-Crystallin Are Recognized and Bound by Human $\gamma \mathrm{B}$-Crystallin Chaperone. J Mol Biol. 2010; 401:134-152. [PubMed: 20621668]

45. Bax A, Grzesiek S. Methodological advances in protein NMR. Acc Chem Res. 1993; 26:131-138.

46. Muhandiram DR, Kay LE. Gradient-Enhanced Triple-Resonance Three-Dimensional NMR Experiments with Improved Sensitivity. J Magn Reson, Ser B. 1994; 103:203-216.

47. Wüthrich, K. NMR of Proteins and Nucleic Acids. John Wiley \& Sons; New York: 1986.

48. Wittekind M, Mueller L. HNCACB, a High-Sensitivity 3D NMR Experiment to Correlate AmideProton and Nitrogen Resonances with the Alpha- and Beta-Carbon Resonances in Proteins. J Magn Reson, Ser B. 1993; 101:201-205.

49. Grzesiek S, Anglister J, Bax A. Correlation of Backbone Amide and Aliphatic Side-Chain Resonances in ${ }^{13} \mathrm{C} /{ }^{15} \mathrm{~N}$-Enriched Proteins by Isotropic Mixing of ${ }^{13} \mathrm{C}$ Magnetization. J Magn Reson, Ser B. 1993; 101:114-119.

50. Sharma D, Rajarathnam K. ${ }^{13} \mathrm{C}$ NMR chemical shifts can predict disulfide bond formation. J Biomol NMR. 2000; 18:165-171. [PubMed: 11101221]

51. Hubbard, SJ., Thornton, JM. NACCESS. Department of Biochemistry and Molecular Biology, University College; London: 1993. 
52. Wagner G, Braun W, Havel TF, Schaumann T, Go N, Wüthrich K. Protein structures in solution by nuclear magnetic resonance and distance geometry. The polypeptide fold of the basic pancreatic trypsin inhibitor determined using two different algorithms, DISGEO and DISMAN. J Mol Biol. 1987; 196:611-639. [PubMed: 2445992]

53. Ramachandran GN, Ramakrishnan C, Sasisekharan V. Stereochemistry of polypeptide chain configurations. J Mol Biol. 1963; 7:95-99. [PubMed: 13990617]

54. Richardson JS. The anatomy and taxonomy of protein structure. Adv Protein Chem. 1981; 34:167339. [PubMed: 7020376]

55. Hutchinson EG, Thornton JM. The Greek key motif: extraction, classification and analysis. Protein Eng, Des Sel. 1993; 6:233-245.

56. Hejtmancik JF, Wingfield PT, Sergeev YV. $\beta$-Crystallin Association. Exp Eye Res. 2004; 79:377383.

57. Platzer G, Okon M, McIntosh LP. pH-dependent random coil ${ }^{1} \mathrm{H},{ }^{13} \mathrm{C}$, and ${ }^{15} \mathrm{~N}$ chemical shifts of the ionizable amino acids: A guide for protein pK a measurements. J Biomol NMR. 2014; 60:109_ 129. [PubMed: 25239571]

58. Takashima, S. Phys Princ Tech Protein Chem. Elsevier; Amsterdam: 1969. Dielectric Properties of Proteins. 1. Dielectric Relaxation.

59. Shiels A, Bennett TM, Hejtmancik JF. Cat-Map: putting cataract on the map. Mol Vision. 2010; 16:2007-2015. 


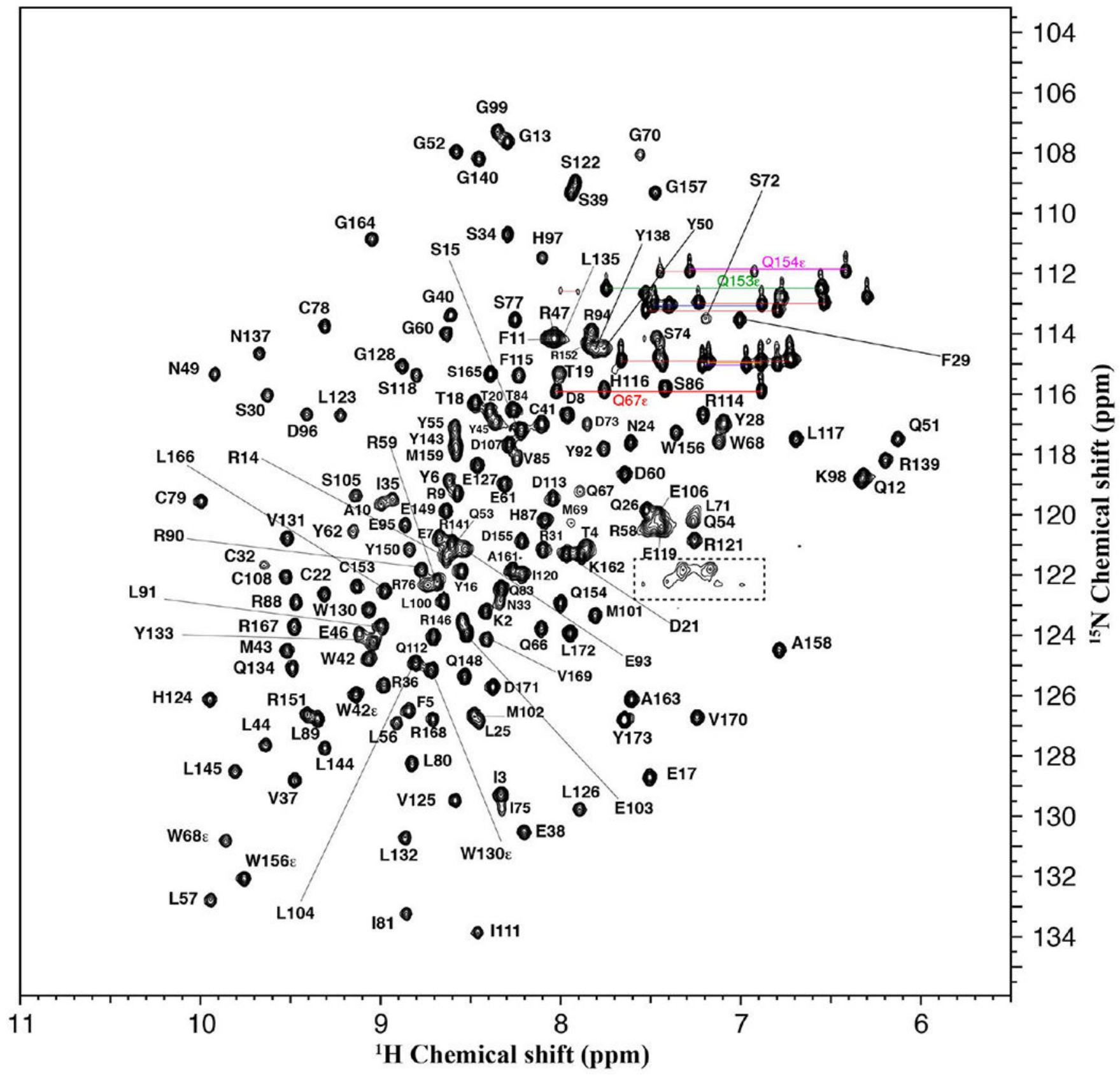

Figure 1.

$600 \mathrm{MHz}{ }^{1} \mathrm{H}-{ }^{15} \mathrm{~N}$ HSQC spectrum of HGC. Sequence-specific assignments are indicated on the spectrum. Horizontal lines connect resonances of side-chain amide protons. The weak resonances (boxed) most probably originate from arginine and or lysine side chains. 

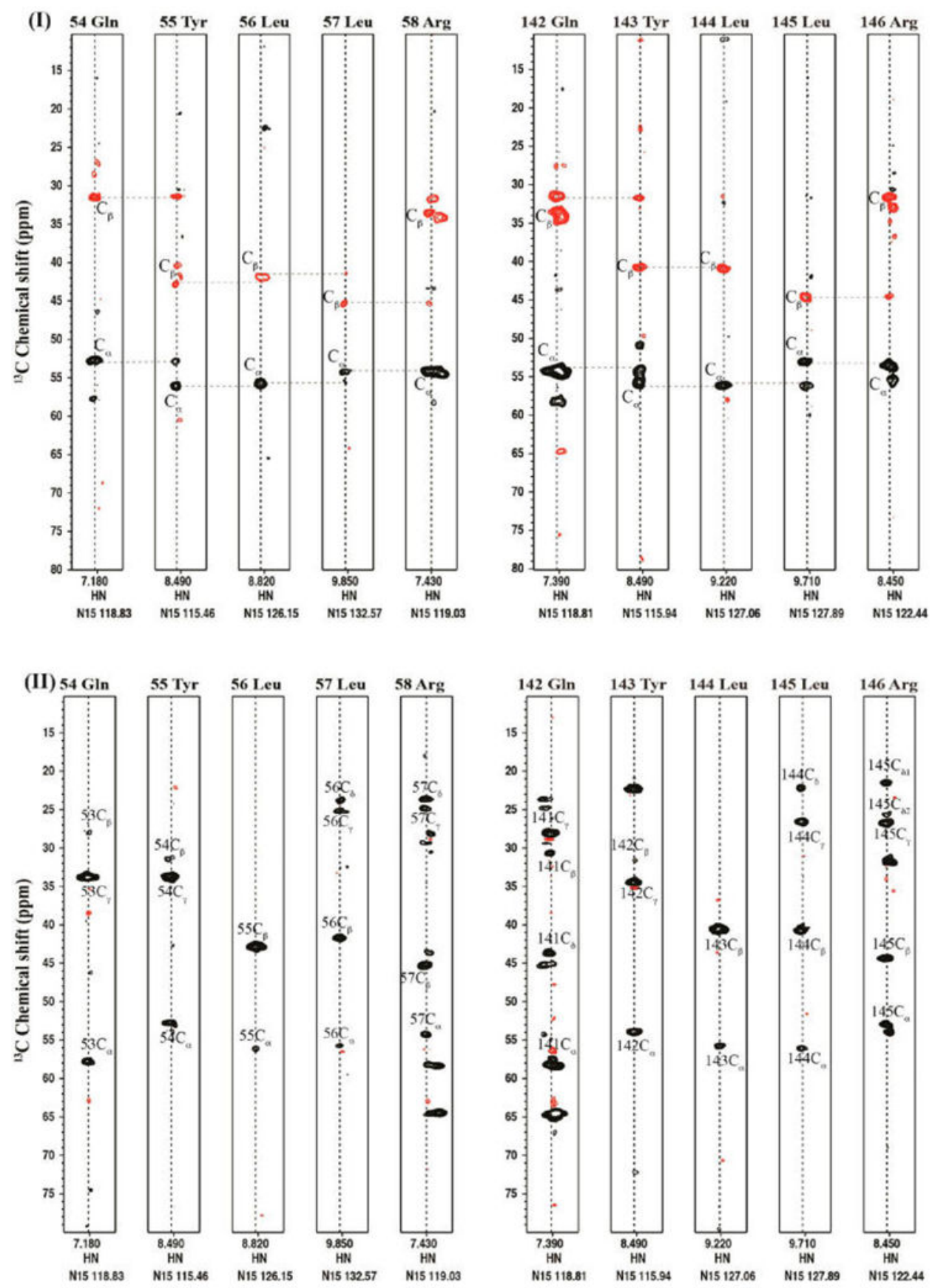

Figure 2.

Strip plot showing sequence-specific correlations in the 3D HNCACB and CC(CO)NHTOCSY spectra. (I) Sequential connectivity walk that provides unambiguous assignments for the identical sequence elements in two domains of HGC. (II) Carbon side-chain skeleton for the same stretches of sequence as observed in the $\mathrm{CC}(\mathrm{CO}) \mathrm{NH}$-TOCSY experiments. 


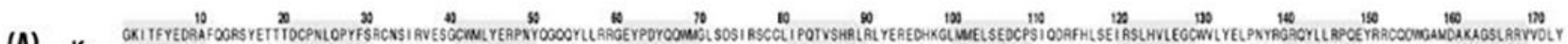

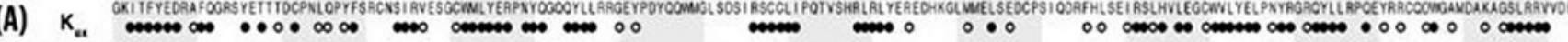
$d_{x}(d)$ (d)

(B)
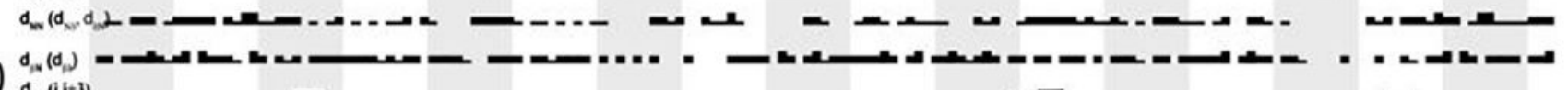

$d a(i+3)$

dist)

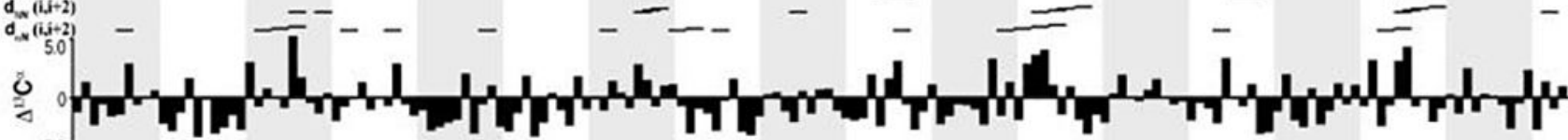

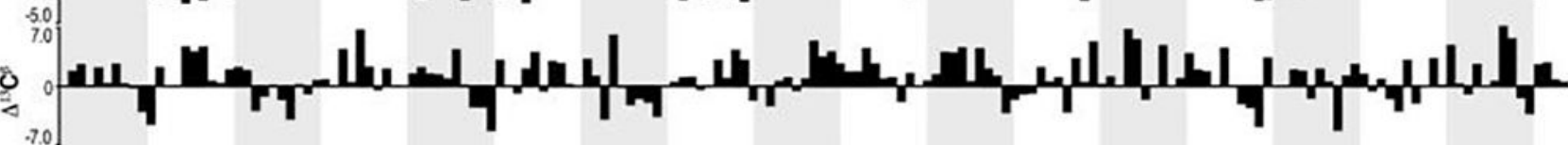

(C)
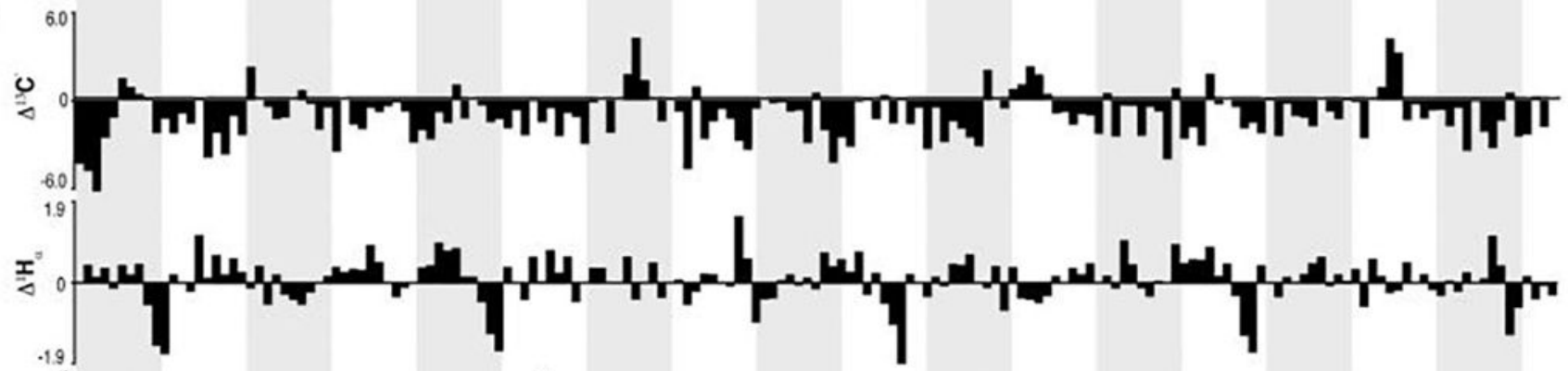

(D)

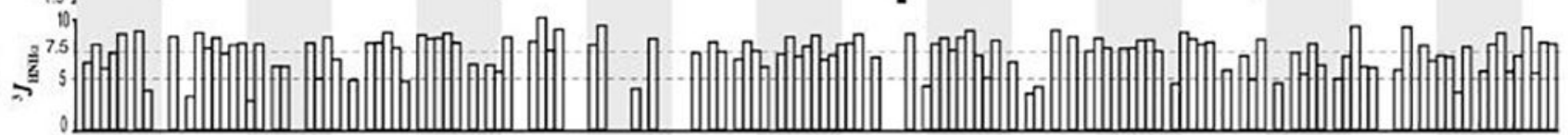

(E)

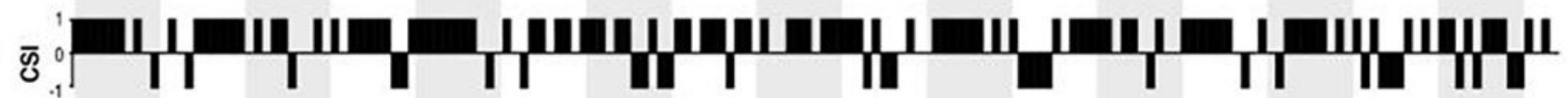

(F)

Figure 3.

Secondary structure identification. (A) H/D exchange experimental data. Filled circles identify residues whose backbone amide protons were protected for up to $>10 \mathrm{~h}$, and empty circles correspond to $<10 \mathrm{~h}$. (B) Summary of short- and medium-range ${ }^{1} \mathrm{H}-{ }^{1} \mathrm{H}$ NOE connectivities observed in HGC. For the sequential ${ }^{1} \mathrm{H}-{ }^{1} \mathrm{H}$ NOE connectivities $\left(d_{a \mathrm{~N}}, d_{\mathrm{NN}}\right.$, and $\left.d_{\beta \mathrm{N}}\right)$, thick and thin bars indicate strong and weak NOE intensities, respectively. The observed medium-range NOEs $\left[d_{a \mathrm{~N}}(i, i+3), d_{a \mathrm{~N}}(i, i+4), d_{\mathrm{NN}}(i, i+2)\right.$, and $\left.d_{a \mathrm{~N}}(i, i+2)\right]$ are indicated by lines connecting the two residues that are related by the NOE. (C) $\Delta^{13} \mathrm{C}_{a}$, $\Delta^{13} \mathrm{C}_{\beta}, \Delta^{13} \mathrm{C}^{\prime}$, and $\Delta^{1} \mathrm{H}_{a}$ secondary chemical shift values plotted vs residue number. (D) ${ }^{3} J_{\mathrm{HNH} a}$ coupling constant values obtained from a 3D HNHA experiment plotted vs residue number. (E) CSI (chemical shift index) plot of HGC with respect to residue number. Helices, $\beta$-strands, and loops are identified by CSI values of $-1,1$, and 0 , respectively. (F) Secondary structure based on the experimental methods given above. 

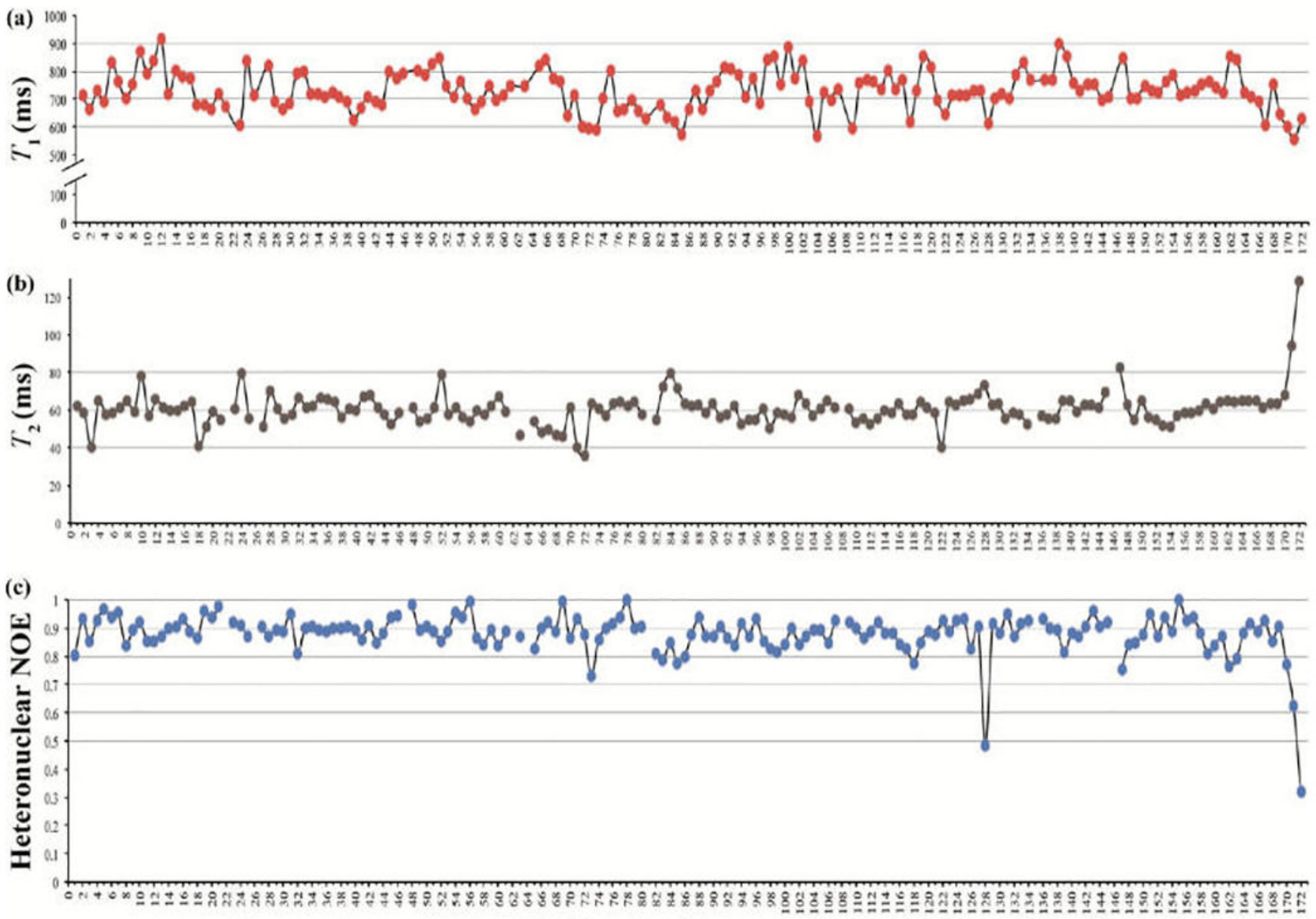

\section{Residue number}

Figure 4.

${ }^{15} \mathrm{~N} T_{1}$ and $T_{2}$ relaxation times, measured on an Agilent $600 \mathrm{MHz}$ NMR spectrometer $\left(\gamma_{\mathrm{N}}=\right.$ $60 \mathrm{MHz}$ ). (a) $T_{1}$, (b) $T_{2}$, and (c) heteronuclear NOE vs residue number. 

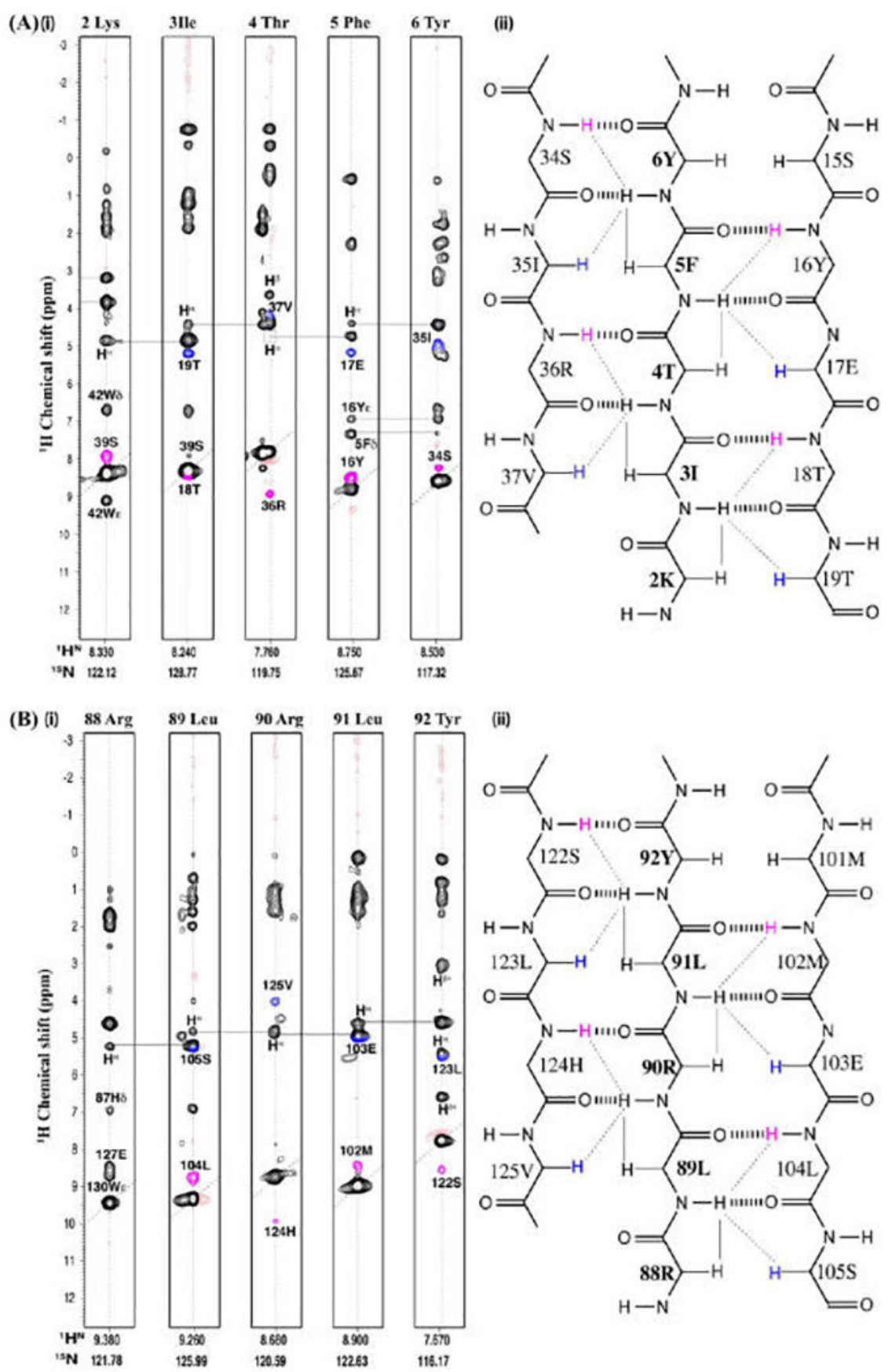

Figure 5.

(A) Strip plot of ${ }^{1} \mathrm{H}^{\mathrm{N}}-{ }^{1} \mathrm{H}$ NOEs of residues 2-6 of HGC, which are present in $\beta$-sheet A. (i) The horizontal line indicates short-range NOE $\left({ }_{i-1} \mathrm{H}^{a}\right.$ to ${ }_{i} \mathrm{H}^{\mathrm{N}}$ NOEs $)$. Peaks colored blue and pink correspond to $\mathrm{H}^{a} \mathrm{H}^{\mathrm{N}}$ NOEs and $\mathrm{H}^{\mathrm{N}} \mathrm{H}^{\mathrm{N}}$ NOEs, respectively. (ii) This represents $\beta$-sheet A topology, in which long-range $d_{a \mathrm{~N}}(i, j)$ and $d_{\mathrm{NN}}(i, j){ }^{1} \mathrm{H}-{ }^{1} \mathrm{H}$ NOEs are indicated by a dashed line and short-range $d_{a \mathrm{~N}}(i-1, i){ }^{1} \mathrm{H}-{ }^{1} \mathrm{H}$ NOEs are indicated by a solid line. (B) Strip plot of ${ }^{1} \mathrm{H}-{ }^{1} \mathrm{H}$ NOEs of residues 88-92 of HGC, which are present in $\beta$-sheet C. (i) The horizontal line indicates short-range NOE $\left({ }_{i-1} \mathrm{H}^{a}\right.$ to ${ }_{i} \mathrm{H}^{\mathrm{N}}$ NOEs). Peaks colored blue and 
pink correspond to $\mathrm{H}^{a} \mathrm{H}^{\mathrm{N}}$ NOEs and $\mathrm{H}^{\mathrm{N}} \mathrm{H}^{\mathrm{N}}$ NOEs, respectively. (ii) This represents the $\beta$ sheet $\mathrm{C}$ topology, where long-range $d_{a \mathrm{~N}}(i, j)$ and $d_{\mathrm{NN}}(i, j){ }^{1} \mathrm{H}-{ }^{1} \mathrm{H}$ NOEs are indicated by a dashed line and short-range $d_{a \mathrm{~N}}(i-1, i){ }^{1} \mathrm{H}-{ }^{1} \mathrm{H}$ NOEs are indicated by a solid line. 

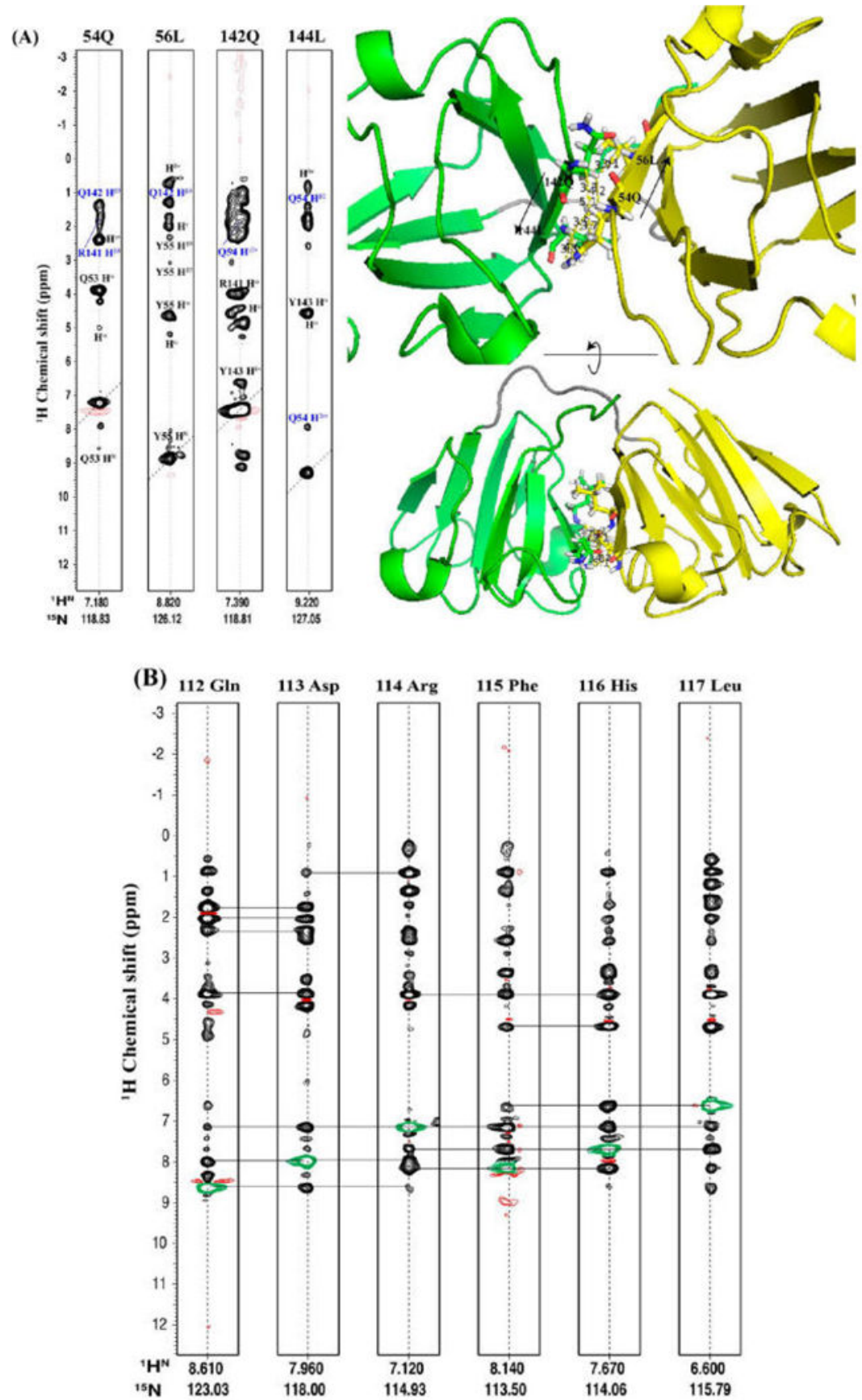

Figure 6.

Strip plot of ${ }^{1} \mathrm{H}-{ }^{1} \mathrm{H}$ NOEs. (A) ${ }^{1} \mathrm{H}-{ }^{1} \mathrm{H}$ NOEs of residues such as 54Q, 56L, 142Q, and $144 \mathrm{~L}$, which are involved in the domain interface. A dashed diagonal line indicates their amide protons, whereas NOEs colored blue are the long-range ${ }^{1} \mathrm{H}^{\mathrm{N}}-{ }^{1} \mathrm{H}$ NOEs. Shown at the top right are the ribbon diagrams of protein, in which the $\mathrm{N}$-terminal domain is colored yellow and the C-terminal domain green. In this ribbon diagram, long-range NOEs are indicated in distances. (B) NOEs of residues 112-117 of HGC, which are present in the $a$ - 
helical loop. Peaks colored green correspond to the backbone amide proton of the same residue. 

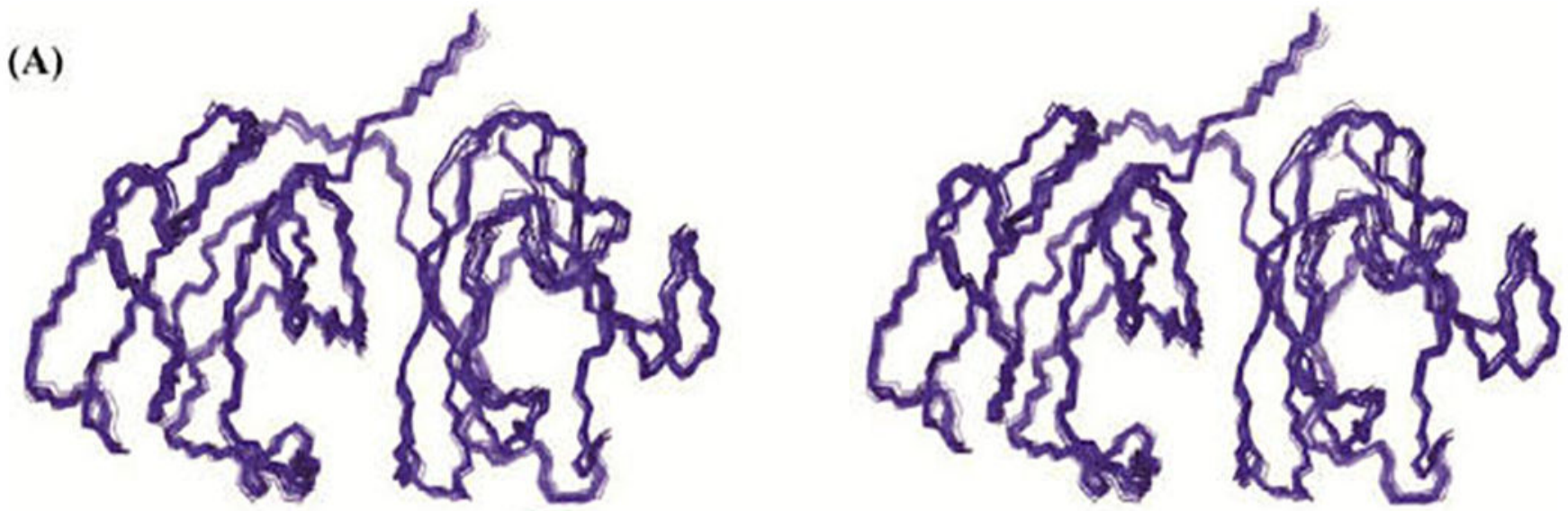

(B)

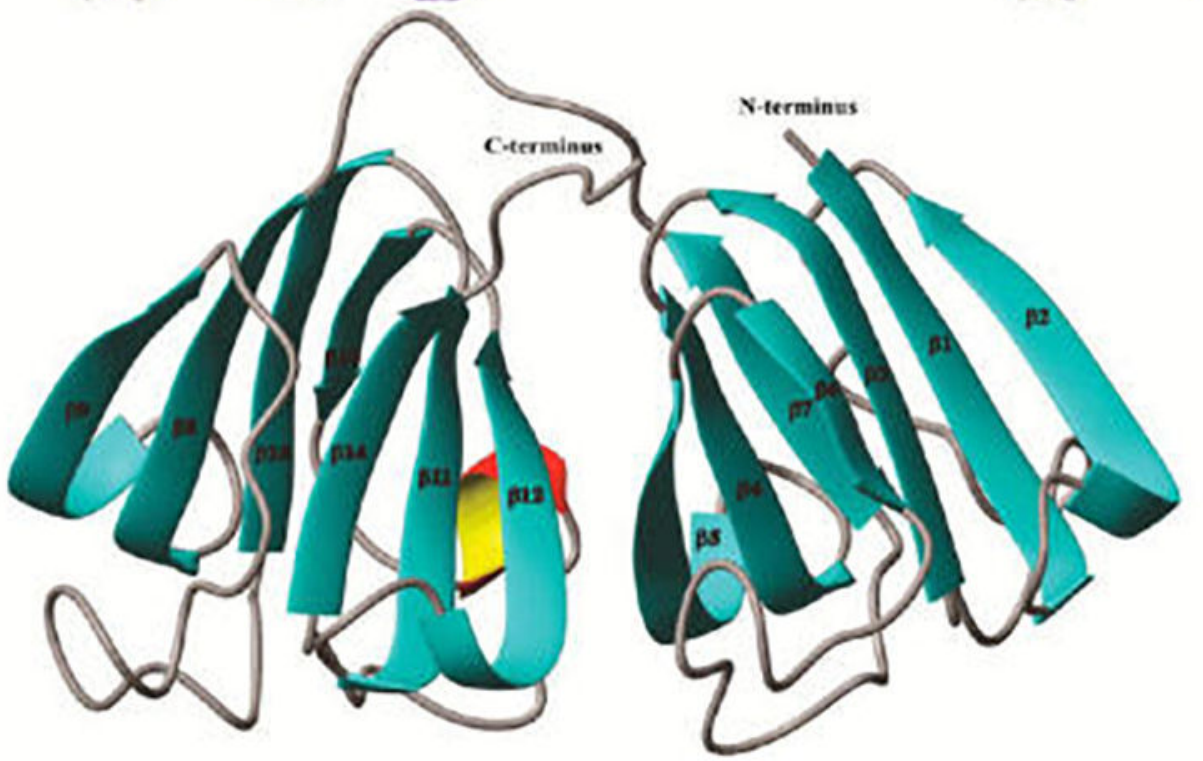

Figure 7.

(A) Stereospecific representation of the ensemble of 20 low-energy conformers of HGC. The structures have been superposed on the backbone ( $\mathrm{N}, \mathrm{C}^{a}$, and $\mathrm{C}^{\prime}$ atoms). (B) Ribbon representation of the lowest-energy conformer of HGC. 
A
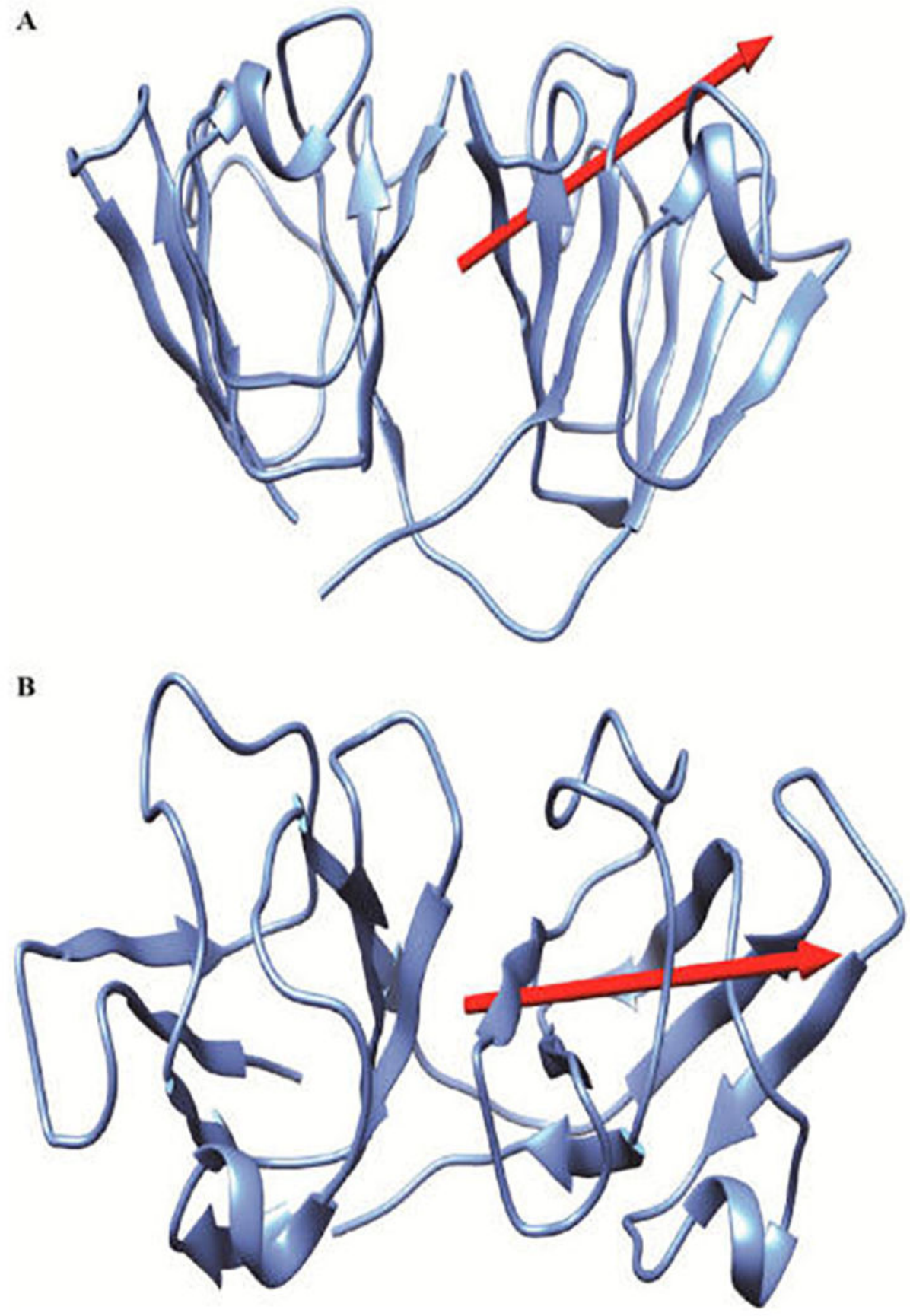

Figure 8.

NMR structure (structure 1) of HGC, with the N-terminal domain to the left, and the computed dipole moment shown as a red arrow. The dipole moment is 274.4 D. (A) Front view of the protein. (B) Top view. 
A

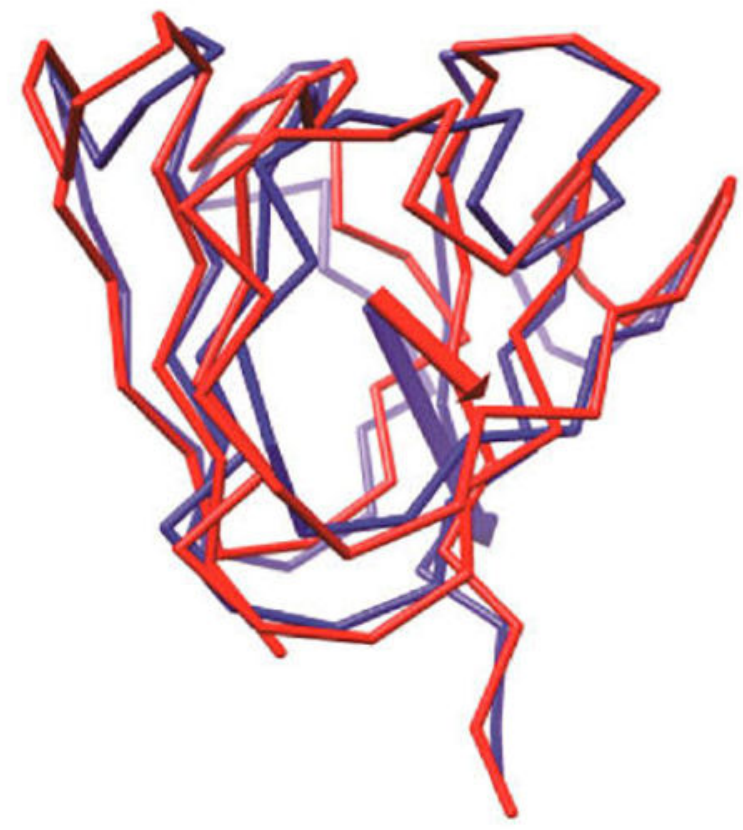

B

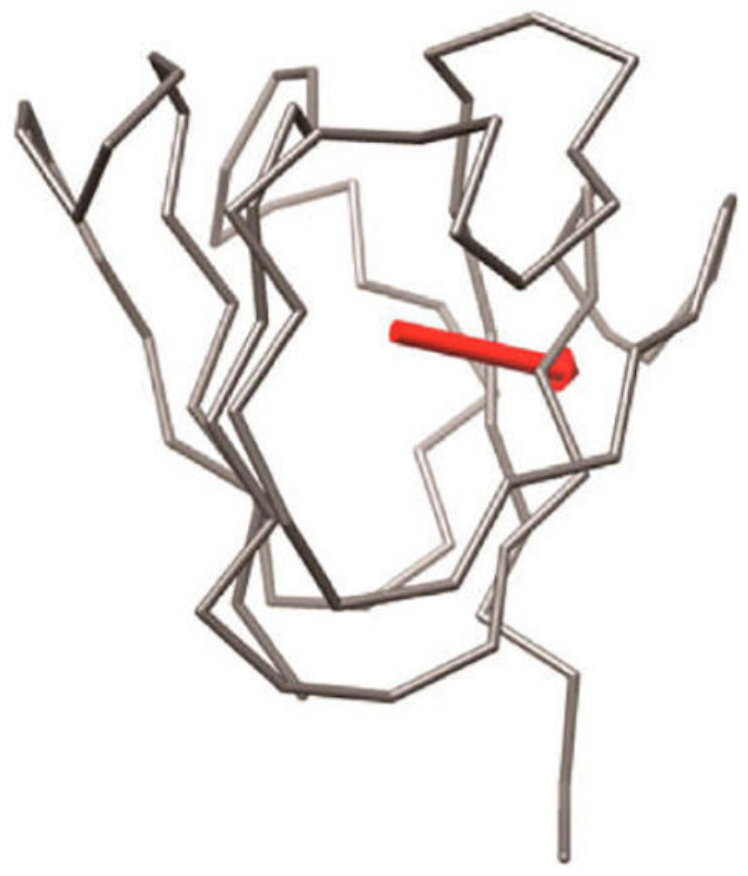

Figure 9.

(A) Manually superimposed peptide backbone of the N-terminal domain of HGC (red) and that of MGC (PDB entry 2v2u), chain A (blue). Dipole moments for each structure are shown in the corresponding color. Dipole moments were calculated for structures with side chains but are shown here only as the backbone, for the sake of visual clarity. (B) Similar structure of the N-terminal domain of BGB and the corresponding dipole moment. The lengths of the arrows depicting the dipole moment are scaled to their magnitudes. Their 
magnitudes are 61.3 D for N-terminal HGC, 139.2 D for the N-terminal MGC_A chain, and 88.0 D for N-terminal BGB. 


\section{Table 1}

NMR and Refinement Statistics for Protein Structures

\begin{tabular}{|c|c|}
\hline \multicolumn{2}{|l|}{ no. of NOE-based distance restraints } \\
\hline total & 1960 \\
\hline intraresidue $(|i-\jmath|=0)$ & 594 \\
\hline sequential $(|i-\lambda|=1)$ & 629 \\
\hline medium-range $(1<|i-j| \leq 4)$ & 148 \\
\hline long-range $(|i-j| \geq 5)$ & 589 \\
\hline NOE restraints per residue & 11.5 \\
\hline no. of hydrogen bond restraints & 170 \\
\hline no. of dihedral angle restraints & 442 \\
\hline total no. of restraints & 2572 \\
\hline total no. of restraints per residue & 14.87 \\
\hline total no. of structures calculated & 200 \\
\hline no. of structures used & 20 \\
\hline \multicolumn{2}{|l|}{ no. of restraint violations } \\
\hline dihedral angles of $>5^{\circ}$ & 0 \\
\hline distances of $>0.2 \AA$ & 0 \\
\hline van der Waals & 0 \\
\hline \multicolumn{2}{|l|}{ Ramachandaran plot (Procheck) (\%) } \\
\hline most favored regions & 81.9 \\
\hline additionally allowed regions & 18.1 \\
\hline generously allowed regions & 0.0 \\
\hline total allowed regions & 100.0 \\
\hline disallowed regions & 0.0 \\
\hline \multicolumn{2}{|c|}{ Ramachandaran plot (Molprobity) (\%) } \\
\hline most favored regions & 95.4 \\
\hline allowed regions & 4.1 \\
\hline total allowed regions & 99.5 \\
\hline disallowed regions & 0.5 \\
\hline \multicolumn{2}{|c|}{ rmsd from mean structure coordinate $(\AA)$} \\
\hline backbone & 0.6 \\
\hline average heavy atom & 1.0 \\
\hline
\end{tabular}

Biochemistry. Author manuscript; available in PMC 2017 April 14. 


\section{Table 2}

$\mathrm{C}^{\beta}-\mathrm{C}^{\beta}$ Distances (angstroms) for Residue Pairs across the Interdomain Interface

\begin{tabular}{lccc}
\hline & \multicolumn{3}{c}{ distance } \\
\cline { 2 - 4 } Protein & $\mathbf{4 3 - 1 4 4}$ residue pair & $\mathbf{5 6 - 1 3 1}$ residue pair & $\mathbf{8 1 - 1 6 9}$ residue pair \\
\hline human $\gamma \mathrm{C}$ (model) & 8.7 & 6.9 & 6.4 \\
human $\gamma \mathbf{C}$ (NMR, this study) & $\mathbf{4 . 2}$ & $\mathbf{5 . 5}$ & $\mathbf{5 . 2}$ \\
mouse $\gamma \mathrm{C}$ & 5.2 & 5.2 & 5.5 \\
human $\gamma \mathrm{D}$ & 5.4 & 5.2 & 5.4
\end{tabular}

